\title{
Cystic Fibrosis Lung Disease: An Overview
}

\author{
Nelson L Turcios
}

\author{
Introduction \\ Clinical Manifestations \\ Establishing the Diagnosis \\ Cystic Fibrosis Genotype/Phenotype \\ Pathogenesis of Cystic Fibrosis Lung Disease \\ Endobronchial Infections \\ Emerging Bacterial Infections \\ Fungal Infections \\ Pulmonary Exacerbations \\ Airway Clearance and Maintenance Medications \\ Atelectasis \\ Airway Hyper-Reactivity \\ Pulmonary Emergencies in Cystic Fibrosis \\ Hemoptysis \\ Pneumothorax \\ Respiratory Failure \\ Diagnostic Imaging \\ Pulmonary Function Testing \\ Infection Control \\ Lung Transplantation \\ New Treatment Strategies \\ Summary
}

\begin{abstract}
Although better insights into the natural course of cystic fibrosis (CF) have led to treatment approaches that have improved pulmonary health and increased the life expectancy of individuals with this disorder, lung disease remains the main cause of morbidity and mortality in patients with CF. Evidence suggests that airway epithelial defects in ions-water transport lead to dehydrated mucus, impaired mucus clearance, and mucus adhesion to airway surfaces. An increase in mucin secretion is also suggested by the formation of endobronchial mucus plaques and plugs, which become the main sites of air flow obstruction, infection, and inflammation conducing to early small airways disease followed by the development of bronchiectasis. The lung involvement is usually progressive with intermittent exacerbations. Aggressive management and advances in treatment delay, but, do not prevent progression of lung disease. Respiratory failure ensues and is the major cause of death. The lung parenchyma is virtually untouched for much of the course of the disease. This review focuses on the lung involvement in cystic fibrosis and summarizes new developments on the diagnostic approach of $\mathrm{CF}$ and pathogenesis of related lung disease. Current therapeutic modalities, novel therapies targeting the basic genetic defect, and lung transplantation are also reviewed. Key words: cystic fibrosis; cystic fibrosis transmembrane regulator; airway surface liquid; mucociliary clearance; endobronchial infection and inflammation; Pseudomonas aeruginosa; bronchiectasis. [Respir Care 2020;65(2):233-251. (C) 2020 Daedalus Enterprises]
\end{abstract}




\section{CF OverVIEW}

\section{Introduction}

Cystic fibrosis (CF), a single-gene disease with autosomal recessive inheritance, is caused by a mutation (chemical change) in the $C F$ gene aptly named the CFTR (cystic fibrosis transmembrane conductance regulator) protein. ${ }^{1}$ The CFTR protein forms a chloride channel that is critical to efficient mucus transport. Mutations in CFTR disrupt chloride secretion, sodium reabsorption, and water transport, leading to mucus hyperconcentration and decreased mucociliary clearance. ${ }^{1}$ Dehydrated mucus secretions lead to endobronchial infection with a narrow spectrum of distinctive bacteria and exaggerated inflammatory response, which result in the development of severe bronchiectasis rather than fibrosis and, eventually, respiratory failure. ${ }^{2}$

In 2016, the median predicted survival among individuals born with CF was $47.7 \mathrm{y}$, compared to $41.2 \mathrm{y}$ in 2015. ${ }^{3}$ More than half of patients with CF living in the United States are adults. ${ }^{3}$ These improvements in survival are due to early diagnosis, better understanding of the natural course of this disease, and better treatments, which include aggressive nutritional support, enhanced mucociliary clearance and mucus drainage, prompt antimicrobial and anti-inflammatory therapy, timely treatment of pulmonary exacerbations, infection control measures in and outside CF centers, and rapid identification and treatment of CF-related complications. ${ }^{4}$ Although touching on various important $\mathrm{CF}$ lung disease-related topics, this overview does not intend to be comprehensive; rather, it provides suggested readings for those interested in keeping abreast of new advances in particular areas.

\section{Clinical Manifestations}

The earliest manifestations of $\mathrm{CF}$ are gastrointestinal and nutritional disorders. Approximately 15\% of infants with CF present with meconium ileus at birth. ${ }^{5}$ Destruction of acinar pancreatic tissue, pancreatic duct obstruction, and lack of enzymatic activity lead to malabsorption of fats and proteins and failure to thrive.5,6 Other nonpulmonary presenting clinical findings that suggest the need for a sweat test are electrolyte imbalance, rectal prolapse, diabetes mellitus, recurrent pancreatitis, and male infertility (due to congenital bilateral absence of the vas deferens). ${ }^{5}$ Additional manifestations include digital clubbing, chronic sinusitis, and nasal polyps; biliary cirrhosis,

\footnotetext{
The author has disclosed no conflicts of interest.
}

Correspondence: Nelson L Turcios MD, Medical Staff Office, Robert Wood Johnson University Hospital, One Robert Wood Johnson Place, New Brunswick, NJ 08901. E-mail: nlturcios@gmail.com.

DOI: $10.4187 /$ respcare.06697 although extremely rare, may be an isolated presenting feature of $\mathrm{CF} .^{5}$

The onset and progression of clinical manifestations of lung disease in $\mathrm{CF}$ is highly variable. ${ }^{7}$ Respiratory manifestations are uncommon in the newborn period, but older infants may present with persistent coughing, recurrent wheezing, tachypnea, and frequent lung infections. In some countries, where neonatal screening for $\mathrm{CF}$ is not available, these respiratory symptoms are often misdiagnosed as asthma or "recurrent bronchitis," and, as a result, appropriate therapy is frequently delayed. ${ }^{7}$ As the lung disease progresses, the patient with CF may experience shortness of breath and exercise intolerance. ${ }^{7}$

\section{Establishing the Diagnosis}

Although CF is more prevalent among whites, the disease has been reported among all ethnicities and nationalities. Therefore, CF should not be excluded in a patient with suggestive clinical findings solely because of that patient's ethnicity. The estimated prevalence rate in whites is 1:2,500; in Hispanics 1:3,500; in African Americans 1:15,100; in Asians, native Hawaiians and Pacific Islanders $1: 31,000$ to $1: 100,000 .^{2}$

Consensus guidelines from the Cystic Fibrosis Foundation review the diagnostic approach to $\mathrm{CF} .{ }^{8}$ Figure 1 provides an algorithm to recommend a sweat test for individuals suspected of having $\mathrm{CF}$ because of a positive newborn screening result (defined as any result other than normal), the appearance of signs or symptoms, or a family history of CF. ${ }^{8}$ The most commonly performed newborn screening method involves measuring the levels of immunoreactive trypsinogen, a pancreatic enzyme precursor, in blood spots, which has a high sensitivity but low specificity and yields many false-positive results. If the immunoreactive trypsinogen level is high, some states repeat the test. Most states perform both an immunoreactive trypsinogen test and a DNA analysis. It is important to note that even this DNA testing is still only a "screening test" for $\mathrm{CF}$ and all infants with a positive newborn screening need to be referred for a diagnostic sweat test. ${ }^{8}$

A sweat chloride level of $\geq 60 \mathrm{mmol} / \mathrm{L}$ confirms a clinical diagnosis of $\mathrm{CF}$. A sweat chloride level in the normal range $(<29 \mathrm{mmol} / \mathrm{L})$ indicates that $\mathrm{CF}$ is improbable; however, sweat chloride values in the normal range have been reported in the presence of certain CFTR mutations, ${ }^{9}$ thus genetic analysis may be indicated in some clinical situations even if the sweat test is in the normal range. ${ }^{10}$ For individuals with intermediate sweat chloride level of $30-59 \mathrm{mmol} / \mathrm{L}$, genetic analysis is required. Further testing for CFTR function, such as nasal potential difference, and intestinal current measurement may also be indicated and performed in a specialized diagnostic $\mathrm{CF}$ care center. 


\section{CF OVERVIEW}

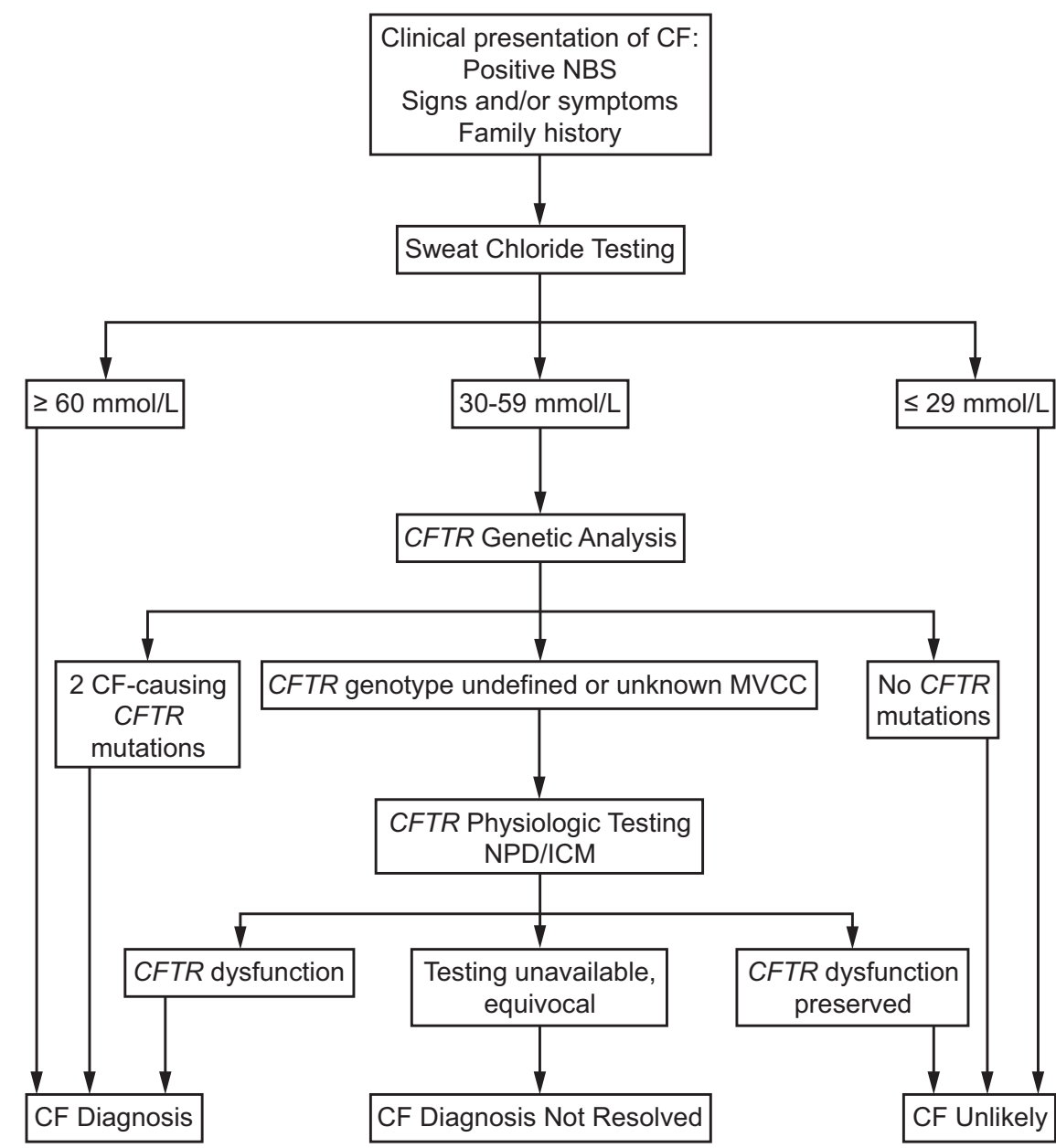

Fig. 1. Simplified algorithm for how consensus statements should be applied to individuals suspected of having cystic fibrosis. From Reference 8, With permission. CF = cystic fibrosis; CFTR = cystic fibrosis transmembrane regulator; NBS = newborn screening; MVCC = mutation of varying clinical consequence; NPD = nasal potential difference; ICM = intestinal current measurement.

Some infants with a positive newborn screening and sweat chloride levels of $30-59 \mathrm{mmol} / \mathrm{L}$ (or even $\leq 29 \mathrm{mmol} / \mathrm{L}$ if 2 CF mutations are detected) are designated as having CFTRrelated metabolic syndrome; in Europe they are designated CF screen-positive inconclusive diagnosis. ${ }^{8}$ These infants should be referred to a CF center for follow up on the development of clinical manifestations of CF and to repeat sweat testing over several years to monitor for the potential of sweat chloride levels rising into the abnormal range. Clinical follow up is also recommended for subjects with sweat chloride values in the range of $30-39 \mathrm{mmol} / \mathrm{L}$ without any signs or symptoms of CF. Thus, genetic testing, which involves additional costs and possibly inconclusive results, could be avoided. ${ }^{11}$

Many individuals born in United States prior to 2010 have not been screened; however, the algorithm remains applicable to these individuals. ${ }^{12}$ The diagnosis of CF in the non-screened population may be difficult because of the age of onset, possibility of partial or complete pancreatic sufficiency, and the absence of typical clinical features (ie, pulmonary and gastrointestinal) as a result of variable levels of CFTR dysfunction. Presenting manifestations may include pancreatitis, respiratory symptoms, chronic sinusitis, and male infertility. ${ }^{12}$

\section{Cystic Fibrosis Genotype/Phenotype}

The functional consequences of the CFTR mutations may be grouped into 6 classes that represent alterations of normal protein production, trafficking, and function at the epithelial cell membrane, or a combination of these abnormalities. These classes of mutations give rise to a range of phenotypes extending from classic CF to single-organ involvement. ${ }^{13}$ Class I mutations cause a total or partial lack of production of a functional CFTR protein, most commonly as a result of a premature termination codon. Class II mutations lead to misfolding of the protein and failure of trafficking to the cell surface. Class III are mutations where the gating mechanism fails to open in response to intracellular signals. The majority of patients 
Table 1. Mutation Classification

\begin{tabular}{|c|c|c|c|c|c|}
\hline Disease Severity & Class & Mutation & CFTR & Examples & Prevalence, $\%$ \\
\hline \multirow[t]{3}{*}{ Severe disease } & I & Nonsense; frame-shift & No functional CFTR & G542X & 12 \\
\hline & II & Missense; amino acid deletion & $C F T R$ trafficking defect, some $C F T R$ & F508del & 87 \\
\hline & III & Missense & Abnormal channel function, block in regulation & G551D & 5 \\
\hline \multirow[t]{3}{*}{ Mild disease } & IV & Missense & $\begin{array}{l}\text { Abnormal channel function, altered } \\
\text { conductance }\end{array}$ & $\begin{array}{l}\mathrm{R} 117 \mathrm{H} \\
\mathrm{D} 1152 \mathrm{H}\end{array}$ & 5 \\
\hline & $\mathrm{V}$ & Missense; splicing defect & Reduced synthesis of $C F T R$ & $\begin{array}{l}3849+10 \mathrm{kbC} \rightarrow \mathrm{T} \\
5 \mathrm{~T} \\
\mathrm{~A} 455 \mathrm{E}\end{array}$ & 5 \\
\hline & VI & Missense & Decreased stability of $C F T R$ & 4326delTC & Rare \\
\hline
\end{tabular}

In general, patients with class I, II, or III mutations exhibit severe disease symptoms. Patients with class IV, V, or VI mutations exhibit mild symptoms. Adapted with permission from ABcomm.

in the Cystic Fibrosis Foundation Patient Registry are in the mutation class I-III grouping, and these mutations characteristically have little or no CFTR function. Class IV mutations demonstrate reduced ion conductance. Class V are splicing mutations that result in reduced amounts of CFTR protein. Class VI mutations possess a shortened half-life. ${ }^{13}$ In relation to disease severity, higher sweat test values are observed among individuals in classes I-III than in classes IV-VI (Table 1).

Although the prevalence of CFTR mutations differs among populations, the most common CFTR mutation is the p.F508del; $85.8 \%$ of individuals in the 2017 Cystic Fibrosis Foundation Patient Registry have at least one copy of this mutation with a homozygous prevalence of $45.3 \%$. There are $>1,800$ CFTR variants reported, although not all cause disease. The CFTR2 database only includes information about 322 of the most common CFTR variants. It is important to note that not all patients with the same variants have the same outcome.

Classes IV-VI mutations retain some residual CFTR function and are more likely to be associated with pancreatic-sufficient CF. ${ }^{10}$ Lung function has a less clear correlation between genotype and phenotype, and even patients of the same genotype will report highly different lung function. ${ }^{14}$ Lung function variability and a lack of clear genotype-phenotype correlation for lung disease means that, for any given patient, there is no reliable way to predict lung function over time. ${ }^{15}$ For more information on CFTR mutation databases, visit www.genet.sickkids.on.ca/ cftr/ and https://www.cftr2.org.

\section{Pathogenesis of CF Lung Disease}

Efficient mucociliary clearance is essential for respiratory health. ${ }^{16}$ The mucociliary clearance apparatus consists of 2 hydrogels: a mucus layer and a periciliary layer. ${ }^{17}$ Effective mucociliary transport is dependent on proper hydration of the airway surface liquid. Mucociliary clearance may be impaired by abnormalities of ciliary motion or by changes in the composition of mucus that make it less responsive to ciliary propulsion. ${ }^{17}$ In healthy persons, airway epithelia can secrete or absorb ions and water, preserving normal airway surface hydration (Fig. 2). ${ }^{18}$ The higher osmotic pressure of the periciliary layer in healthy persons ensures that it is well hydrated, providing appropriate lubrication for ciliary activity and transport of the overlying mucus layer. ${ }^{17} \mathrm{~A}$ well-hydrated mucus layer is transported rapidly from the distal airways toward the trachea.

The abnormal concentration of mucus in the lungs of patients with CF reflects a primary abnormality of airway epithelial ion-water transport. ${ }^{19} \mathrm{In} \mathrm{CF}$, the airway epithelium is susceptible to fluid hyperabsorption because of a defect in the secretion of chloride and bicarbonate anions mediated by the CFTR and by an intact sodium-absorptive path. This abnormal epithelial fluid absorption raises osmotic pressures in the mucus layer that exceed those in the periciliary layer that deplete the airway surface of fluid, leading to hyperconcentrated (dehydrated) mucus, impaired mucus transport, and mucus adhesion to airway surfaces (Fig. 2). ${ }^{18}$

An increase in mucin (the principal component of airway mucus) secretion is suggested by the formation of endobronchial mucus plaques and plugs, ${ }^{20}$ which become the main sites of chronic airway infection, not airway epithelial cell surfaces. ${ }^{21}$ Air-flow obstruction and recurrent bacterial infections are common features of CF lung disease. Endobronchial infection induces an excessive and ineffective inflammatory response characterized by elevated airway levels of neutrophil elastase that contribute to excess mucus adhesiveness and cohesiveness (ie, sticky and stringy).22 A chronic cycle of infection and inflammation is initiated, resulting in damage to the structural integrity of the airways and leading to the development of bronchiectasis. ${ }^{22}$ These features are detected in nearly $30 \%$ of children with CF as early as the age of 3 months and progressing to nearly $60 \%$ at $3 \mathrm{y}$ old (Fig. 3 ). ${ }^{23}$ 


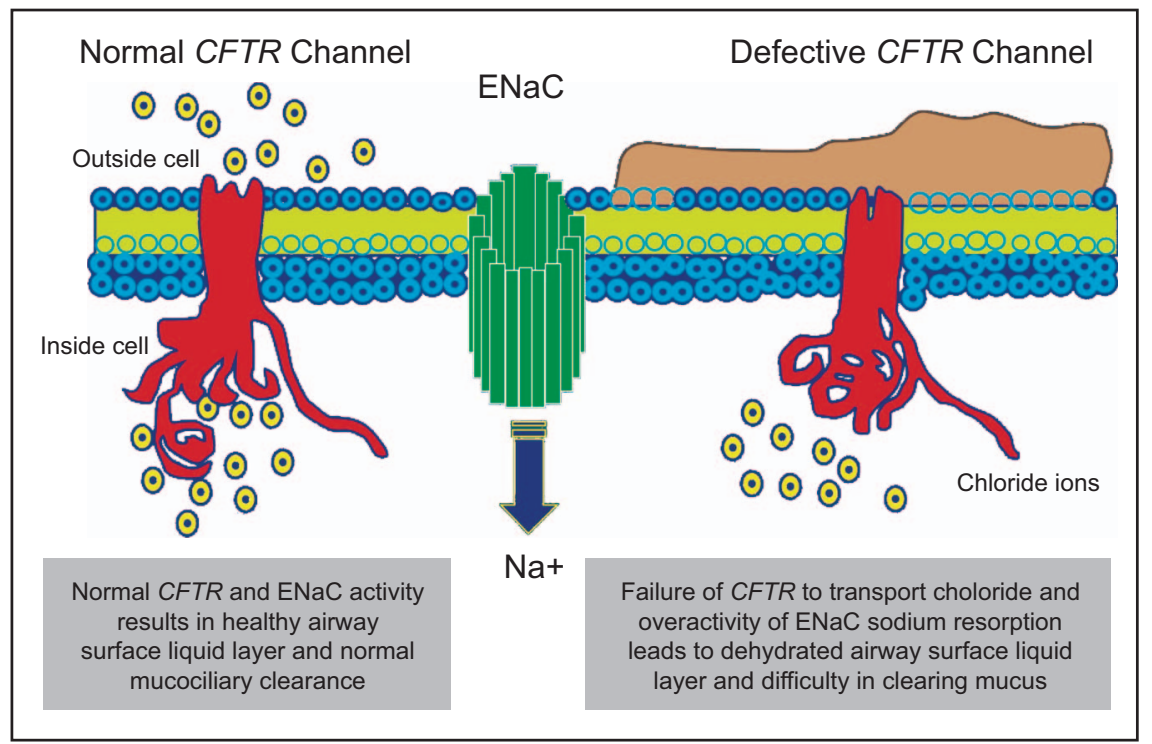

Fig. 2. In healthy people (left), a well-balanced epithelial sodium $\left(\mathrm{Na}^{+}\right)$absorption and secretion of chloride anions hydrates airway surfaces and promotes efficient mucociliary transport. In the CF airway (right), the defective cystic fibrosis transmembrane regulator (CFTR) channel and increased activity of the epithelial sodium channel $(\mathrm{ENaC})$ lead to dehydrated mucus, failed mucus clearance, and mucus adhesion to airway surfaces. The abnormal concentration of mucus in the lungs of patients with cystic fibrosis reflects a primary abnormality of airway epithelial ion transport. Mucus hyperconcentration is a feature of cystic fibrosis. With permission from ABcomm.

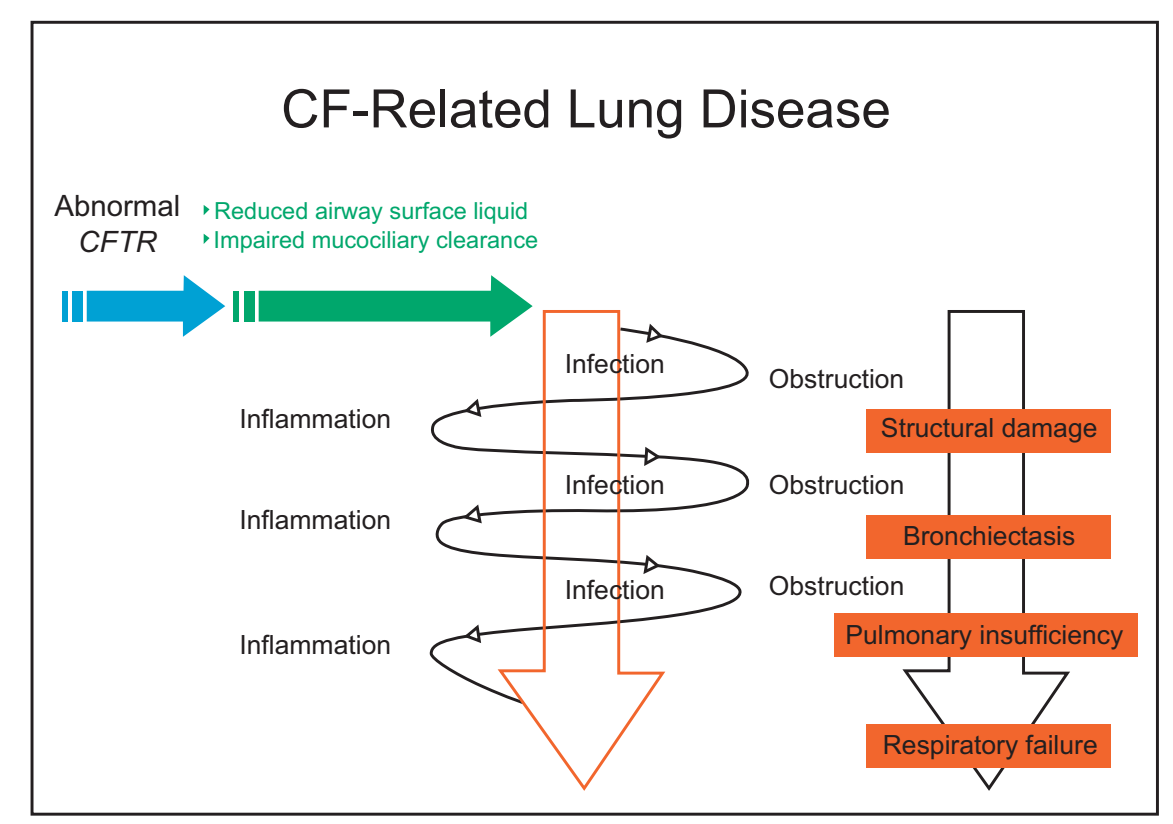

Fig. 3. Mucus hyperconcentration and impaired mucociliary clearance cause air-flow obstruction, infection, and inflammation, which lead to a vicious cycle of intermittent exacerbations and pulmonary complications. Chronic infection and inflammation impair the airways' natural defense mechanisms. Eventually, this cycle damages the structural integrity of the airways. Respiratory failure is responsible for most deaths related to cystic fibrosis (CF). With permission from ABcomm.

\section{Endobronchial Infections}

Hyperconcentrated respiratory secretions lead to chronic airway obstruction, colonization by bacteria, and acute and chronic infection. Changes in the CF microbiome (ie, com- plex and dynamic airway bacterial communities) affect the progression of irreversible lung disease in these patients despite their immune competence. ${ }^{24}$ During the early years of life, a greater diversity of bacteria (eg. Staphylococcus aureus, Haemophilus influenzae) are common. With pro- 


\section{CF OverVIEW}

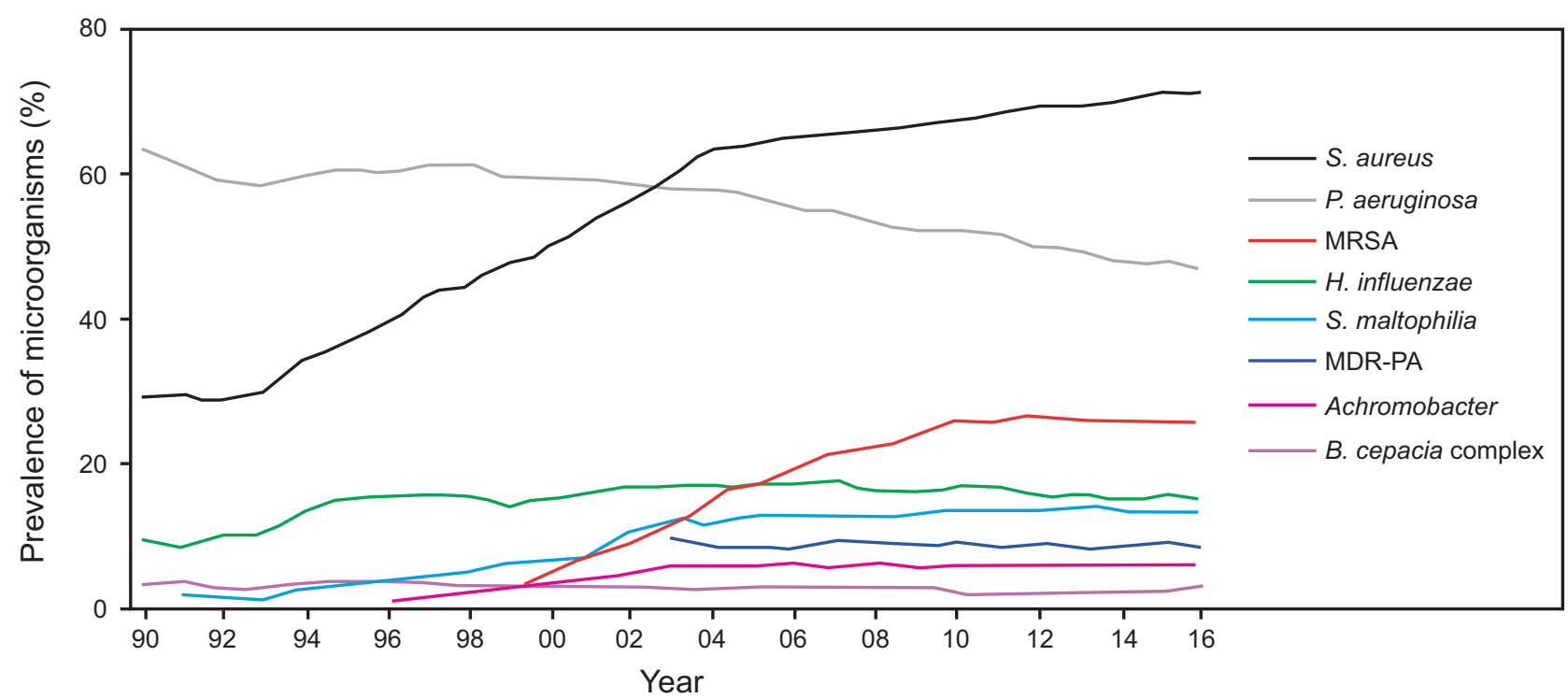

Fig. 4. Proportion of individuals in various age groups who cultured positive for the bacterial species indicated during 2016. MRSA = methicillin-resistant $S$. aureus, MDR-PA = multidrug resistant pseudamona aeruginosa. With permission from the Cystic Fibrosis Foundation.

gressive lung disease, typical CF pathogens (Pseudomonas aeruginosa, Burkholderia cepacia, Achromobacter xylosoxidans) colonize the airway. ${ }^{25}$

The 2016 Cystic Fibrosis Foundation Patient Report registered the prevalence of major respiratory pathogens over time (1990-2016) in patients with CF. ${ }^{3}$ The prevalence of $P$. aeruginosa continues to decrease; however, the prevalence of multi-drug resistant $P$. aeruginosa has remained constant. This may be in part due to the widespread implementation of therapy to eradicate initial $P$. aeruginosa infection (Fig. 4).

$P$. aeruginosa is the most common bacterial pathogen and it is isolated in 55\% of adult patients. ${ }^{26}$ The initial $P$. aeruginosa clinical isolates resemble those found in the natural environment in that they are nonmucoid, susceptible to most antibiotics, and present at low density. Conversion to a mucoid phenotype results in the formation of a self-protective extracellular matrix of glycoproteins (ie, biofilm), which increases its resistance to the host's immunity and antibiotics. This phenotype is associated with a more rapid and progressive decline in lung function, worsening quality of life, increased risk of hospitalization, and reduced survival. ${ }^{27-29} \mathrm{In}$ haled antibiotics directed toward eradicating $P$. aeruginosa are generally successful in $\sim 80 \%$ of subjects across multiple clinical trials. ${ }^{30,31}$ Early $P$. aeruginosa eradication therapy is recognized as contributing to better patient outcomes and reduced treatment costs. ${ }^{31-33}$ However, failed eradication of $P$. aeruginos $a$ with unique phenotypes has been reported. ${ }^{34} \mathrm{~A}$ recent study indicates that early eradication may not be sufficient to eliminate the consequences of $P$. aeruginosa acquisition. ${ }^{35}$
Treatment of chronic mucoid $P$. aeruginosa infections in patients with $\mathrm{CF}$ rarely eradicate the organism from the airways. ${ }^{36}$ Inhaled tobramycin treatment every other month has become a standard of care for patients chronically infected with $P$. aeruginosa. ${ }^{33}$ There is concern, however, that bacterial resistance to tobramycin increases with prolonged administration and tobramycin's positive effects on lung function may wane over time. ${ }^{36}$ During the evolution of CF airway infections, $S$. aureus frequently precedes $P$. aeruginosa. S. aureus is one of the most prevalent respiratory pathogens isolated in the lungs of children and young adolescents with CF. ${ }^{37}$ A period of co-infection with these 2 species is common in these patients. ${ }^{38}$ Oral anaerobic bacteria are frequently detected in $\mathrm{CF}$, and they may contribute to the hypoxic mucus environment in $\mathrm{CF}$ airways and promote colonization with $P$. aeruginosa. ${ }^{39}$

\section{Emerging Bacterial Infections}

The prevalence of methicillin-resistant S. aureus (MRSA) has increased in recent years up to $25 \% .{ }^{40}$ The source of MRSA infection is better recognized than other emerging agents because it is a pathogen of the general population and transmission information is understandable. As a Grampositive organism, MRSA is more resistant to desiccation and may persist on inanimate objects and fomites, making patient transmission possible.

$P$. aeruginosa and MRSA are associated with shortened survival, ${ }^{41}$ increased rate of decline in $\mathrm{FEV}_{1}$, and failure to recover baseline lung function after a pulmonary exacerbation. ${ }^{42}$ Community-acquired MRSA may be spread among asymptomatic household members and a patient 
with $\mathrm{CF}$, as well as among patients with $\mathrm{CF}$. Given the transmission possibilities, infection prevention and control strategies are important, and avoidance of exposure to MRSA is the first line of defense in these patients. Due to its detrimental impact on morbidity and mortality in patients with CF, MRSA demands close surveillance and aggressive management to prevent the establishment of chronic respiratory infection. ${ }^{43}$ Multi-modality efforts to eradicate MRSA have not been shown to have a sustained effect, and this remains an active area of research..$^{43}$ Intravenous vancomycin and oral linezolid are the first line of therapy for MRSA infections in patients with CF. Although the experience with ceftaroline is limited, it may provide an alternative to treat MRSA infection in patients with CF.

Stenotrophomonas species are Gram-negative, obligate aerobic organisms found in aquatic environmental reservoirs. S. maltophilia is a human pathogen and is one of the more common multi-drug resistant pathogens in patients with $\mathrm{CF}$, with a reported prevalence rate up to $30 \% .44$ It is still unclear, however, whether chronic $S$. maltophilia infection is simply a marker of the severity of the disease or whether it is causally related to disease progression. ${ }^{45} \mathrm{~S}$. maltophilia is resistant to $\beta$-lactam drugs and to aminoglycosides. Its empiric treatment includes trimethoprim/sulfamethoxazole in addition to one of the following: piperacillin/tazobactam, levofloxacin, doxycycline, or tygecycline.

Achromobacter species are aerobic, Gram-negative bacilli widely distributed in nature, but rare opportunistic pathogens. There are several 'new' species, but $A$. $x y$ losoxidans is the one most commonly recovered from patients with CF. The rate of endobronchial colonization and infection with this bacteria has increased, but its clinical importance is still debated. ${ }^{46}$ Chronic infection with $A$. $x y$ losoxidans is associated with pulmonary exacerbations and increased need for intravenous antibiotics, which may include meropenem or imipenem in addition to one of the following: trimethoprim/sulfamethoxazole, ciprofloxacin, or minocycline. Isolates are commonly resistant to aminoglycosides, but they are susceptible to high doses of nebulized colistin.

Burkholderia cepacia complex prevalence in patients with CF is $\sim 2-3 \%$, with a greater percentage of adults affected. ${ }^{3}$ B. gladioli, although not part of the B. cepacia complex, is more common than B. cenocepacia, B. multivorans, and $B$. vietnamiensis. Transmission between patients with CF has been associated with serious illness and death. ${ }^{47}$ Two features of these organisms of particular concern in $\mathrm{CF}$ are the potential high level of transmissibility and multi-drug resistance. ${ }^{48}$ Pulmonary infection with $B$. cepacia complex may have variable clinical outcomes, from a chronic asymptomatic infection to a rapid respiratory decline (cepacia syndrome) from systemic invasion, caus- ing endotoxic shock, multi-organ failure, and death. ${ }^{48} \mathrm{Em}$ piric antibiotic therapy for pulmonary infections due to B. cepacia complex includes meropenem in addition to a combination of ceftazidime, chloramphenicol, trimethoprim/sulfamethoxazole, or aztreonam.

Nontuberculous mycobacteria are a complex group of environmental pathogens that cause challenging infectious complications in patients with CF. ${ }^{49,50}$ The Cystic Fibrosis Foundation Patient Registry reported that $12.6 \%$ of patients who were cultured in 2016 had one or more nontuberculous mycobacteria species. ${ }^{3}$ Several risk factors have been identified: allergic bronchopulmonary aspergillosis, malnutrition, diabetes mellitus, and older age, often with residual function mutations and milder CF. Annual cultures for nontuberculous mycobacteria are recommended..$^{51}$ The slow-growing Mycobacterium avium complex and the rapid-growing Mycobacterium abscessus are the most common nontuberculous mycobacteria in CF cases. ${ }^{51}$

The clinical and microbiologic diagnostic criteria for nontuberculous mycobacteria pulmonary disease are the same for patients with and without CF. ${ }^{52}$ In general, nontuberculous mycobacteria pulmonary disease should be suspected in a patient with $\mathrm{CF}$ with positive nontuberculous mycobacteria cultures and increased respiratory or constitutional symptoms, unexpected deterioration in lung function, or progressive radiographic infiltrates that do not respond to intensive airway clearance therapy and antibiotic treatment of typical CF pathogens. ${ }^{53}$ Isolation of nontuberculous mycobacteria from sputum on 3 occasions or the detection of a positive smear is suggestive of nontuberculous mycobacteria disease. Current treatment recommendations are to achieve 12 consecutive months of negative cultures. ${ }^{51,54}$ To date, there have been no randomized controlled trials of nontuberculous mycobacteria treatment in the CF population. ${ }^{55}$

Nocardia species are Gram-positive, intracellular bacteria of low virulence that most frequently cause opportunistic lung infection in immunocompromised hosts. $\mathrm{No}$ cardia species in CF may represent colonization or active infection, which can be difficult to differentiate given the underlying pulmonary involvement, so its clinical relevance remains unclear. ${ }^{56,57}$ For patients with $\mathrm{CF}$ with reported Nocardia species infections, treatment with trimethoprim/sulfamethoxazole alone or in combination with other agents is recommended. .58

\section{Fungal Infections}

Molds, filamentous fungi, and yeasts are commonly present in the respiratory tract of patients with CF. Aspergillus fumigatus is the most commonly detected filamentous fungus in CF, representing well over $90 \%$ of all cultured Aspergillus isolates. A. fumigatus is present in the environment, and spores regularly enter the airways with in- 


\section{CF OverVIEW}

haled air. A. fumigatus may be aerosolized by coughing. This suggests that patient-to-patient transmission is possible, as is the case for other fungi..$^{59}$

Inhaled spores are trapped in the mucous membrane of the upper and lower airways, due to either the thick mucus in the airways providing a source of nutrients supporting growth of the fungus or the failure of mucociliary clearance. As the trapped spores germinate, the cells may secrete proteolytic enzymes, which inhibit their phagocytosis and further facilitate adhesion and colonization within the airways. Another predisposing factor may be the use of broad-spectrum antimicrobials in the management of patients with CF. ${ }^{60,61}$

The prevalence of $A$. fumigatus is reported to be around $15 \% .{ }^{61}$ There is a significant increase in A. fumigatus detection rates when polymerase-chain-reaction tests and DNA sequencing are used to the range of $70-100 \% .^{62,63} \mathrm{~A}$ new classification of the pulmonary involvement in $\mathrm{CF}$ due to A. fumigatus has been proposed based on the combination of 2 new markers (ie, galactomannan and realtime polymerase chain reaction) to standard serological and culture-based tests: i) non-diseased group, ii) serologic allergic bronchopulmonary aspergillosis, iii) Aspergillussensitized, and iv) Aspergillus bronchitis. ${ }^{64,65}$

The diagnosis of allergic bronchopulmonary aspergillosis (ABPA) in CF is difficult and may often be delayed because many of the diagnostic criteria overlap with common manifestations of CF. ${ }^{66}$ Diagnostic criteria suggestive of allergic bronchopulmonary aspergillosis in CF include clinical deterioration that does not respond to antibiotic therapy, elevated total serum immunoglobulin E (IgE) ( $>500 \mathrm{IU} / \mathrm{L}$ ), immediate cutaneous reactivity to A. fumigatus, elevated in vitro $\operatorname{IgE} A$. fumigatus, and serum $\operatorname{IgG}$ to A. fumigatus or precipitating antibodies to $A$. fumigatus by an in vitro test. Additional findings suggestive of allergic bronchopulmonary aspergillosis include pulmonary infiltrates, central bronchiectasis, and peripheral blood eosinophilia. ${ }^{66}$

Patients with ABPA are usually treated with prolonged courses of oral corticosteroids. Although not routinely used for CF-associated allergic bronchopulmonary aspergillosis, monthly intravenous methylprednisolone may reduce potential side effects. ${ }^{67}$ The addition of closely monitored antifungal therapy has been used by some centers in an attempt to reduce the antigen burden in the airways. ${ }^{68}$ Omalizumab, a humanized anti-IgE monoclonal antibody, may be a potentially useful steroid-sparing agent; however, a recent Cochrane review concluded that omalizumab cannot be definitively recommended in CF patients with allergic bronchopulmonary aspergillosis given the absence of supporting data from randomized controlled trials. ${ }^{69}$ Clinical studies suggest that chronic endobronchial cocolonization with $P$. aeruginosa and A. fumigatus is common and is associated with worsened status and prognosis, but it remains unclear whether this relationship contributes to progression of lung disease or is only a marker. ${ }^{70}$

Other less commonly cultured fungi reported in $\mathrm{CF}$ include Scedosporium species, A. terreus, Exophiala dermatitidis, Rasamsonia species, and Trichosporom mycotoxinivorans. ${ }^{71}$ Yeasts also commonly colonize in patients with CF; the Cystic Fibrosis Foundation Patient Registry 2016 reported a prevalence of $17 \%$ for the Candida species. ${ }^{61}$

A better understanding of the complex CF airway microbiome has underscored the limitations of culture-dependent methods. ${ }^{39}$ Newer molecular technologies may be of potential benefit for the detection and identification of bacteria, viruses, fungi, and other organisms present in low quantity that are difficult to recover in culture from $\mathrm{CF}$ specimens and could help define the best treatment regimens to target pathogens without affecting other organisms. ${ }^{72}$

\section{Pulmonary Exacerbations}

Although there is no consensus on the definition of a pulmonary exacerbation, providers and patients with $\mathrm{CF}$ recognize exacerbations not only by the acute worsening of signs and symptoms, but also by their impact on the progression of $\mathrm{CF}$ lung disease and associated increased mortality, ${ }^{73,74}$ short-term decline in $\mathrm{FEV}_{1},{ }^{75}$ reduced quality of life, ${ }^{76}$ and increased health care use..$^{77}$

A significant percentage of the loss of lung function in patients with $\mathrm{CF}$ is probably influenced by pulmonary exacerbations that mark the progression of disease severity. ${ }^{78}$ The decline in lung function may not be fully reversible. ${ }^{79}$ An estimated $25 \%$ of patients who experience a pulmonary exacerbation do not recover to their baseline lung function at 3 months, and 15\% of patients do not recover to baseline lung function at one year after treatment. ${ }^{79}$ Non-responders to intravenous therapy were reported to more likely be female; chronically infected with MRSA, $P$. aeruginosa, or multi-drug resistant $P$. aeruginosa; to have a baseline $\mathrm{FEV}_{1}<40 \%$ of predicted; and a low body mass index. ${ }^{78}$ Previous exacerbations are strongly associated with time to subsequent exacerbations, and shorter courses of intravenous antibiotic treatment for pulmonary exacerbations may increase the risk of treatment failure or retreatment within 30 d. 80

Other factors of incomplete lung function recovery include the etiology of the exacerbation (ie, viral infections) ${ }^{81}$ and patient factors such as the underlying severity of their disease or other comorbidities, such as CF-related diabetes. ${ }^{82}$

Treatment of pulmonary exacerbations usually involves antibiotics and increased airway clearance and caloric intake. ${ }^{83}$ If the exacerbation is caught early and is deemed mild, a common practice is to treat with oral antibiotics. ${ }^{84}$ 
If the exacerbation is moderate to severe, then typically intravenous antibiotics are used. Aminoglycosides may cause nephrotoxicity as well as cochlear and vestibular toxicity. ${ }^{85}$ These toxicities are present in all aminoglycosides, but gentamicin has been shown to greatly increase the risk of acute kidney injury in CF, so gentamicin is rarely used to treat lung infections in patients with CF. ${ }^{86}$ Once-daily dosing of tobramycin is known to result in less nephrotoxicity than a 3-times daily regimen. ${ }^{87}$ Practical guidelines for once-daily dosing of aminoglycosides in adult and pediatric patients with $\mathrm{CF}$ are available. ${ }^{88} \mathrm{Em}$ piric antibiotics for the treatment of $P$. aeruginosa-associated pulmonary exacerbations include tobramycin or amikacin in addition to $\beta$-lactam (eg, ceftazidime, cefepime, piperacillin/tazobactam, imipenem, meropenem, or aztreonam).

There is limited evidence as to whether there is a difference between the efficacy of treatment in the hospital versus treatment in the home. ${ }^{89}$ Current practice within the CF Foundation care center network indicates a median treatment duration of about 2 weeks, with adults more likely to complete some of their treatment at home. ${ }^{3}$ In cases of serious infections, the duration of intravenous antibiotics may be extended using ceftazidime or meropenem.

Severe immediate and delayed IgE-mediated hypersensitivity reactions to intravenous antibiotics are more common in patients with $\mathrm{CF}$ than in the general population. ${ }^{90}$ The risk appears to be highest with $\beta$-lactam antibiotics, particularly piperacillin, with the development of a druginduced fever after the first week of treatment. ${ }^{90}$ Delayed reactions account for $>50 \%$ of hypersensitivity reactions in $\mathrm{CF}$, and so they may occur during intravenous antibiotic therapy in the home. ${ }^{91}$

\section{Airway Clearance and Maintenance Medications}

The development of bronchiectasis (ie, the irreversible abnormal dilatation of affected segmental and subsegmental bronchi) has been reported to be associated with persistent endobronchial infection (especially with $P$. aeruginosa), inflammation, and meconium ileus presentation. ${ }^{23}$ Bronchiectasis first develops in the upper lobes and then progresses to involve the entire lung. 92

Airway clearance techniques should be available to all patients with CF not only to treat bronchiectasis, but also to prevent the progression of the CF lung disease. ${ }^{93}$ The objective of airway clearance is to remove airway secretions and reduce the infectious burden and other irritants. ${ }^{93}$ Airway clearance techniques in individuals with CF should be directed at assisting the body's natural mucociliary clearance system to transport secretions proximally up the airways using a number of methods to increase expiratory air flow and promote the interaction between mucus and air. ${ }^{93,94}$ Airway clearance techniques include modified postural drainage with percussion, active cycle of breathing techniques, and autogenic drainage..$^{93}$

Several oral and chest wall oscillatory devices have been developed. Intrathoracic oscillations are generated orally. Exhalation through these devices generates both oscillations of positive pressure in the airways and repeated accelerations of expiratory air flow that result in improved sputum clearance. The Flutter, the Acapella, the Aerobika, and the intermittent percussive ventilator are among these devices.

Extrathoracic oscillations are generated by forces external to the respiratory system. These oscillations are applied using an inflatable vest attached to a machine, which vibrates at variable frequencies and intensities as set by the operator (eg, high-frequency chest wall oscillation). The Monarch uses oscillating discs, which provide targeted kinetic energy to the lungs to generate air flow and mobilize mucus from the airways; the Vibralung Acoustic Percussor transfers acoustic energy-generated vibrations to the airways during inspiration and expiration to mobilize secretions.

Exercise can be used as a supplement to other forms of airway clearance techniques. Increased flow is expected to generate more interaction between mucus and air, but exercise is different from airway clearance techniques in its goals, its impact on overall well-being, and its prognostic factor on survival. As with other CF therapies, airway clearance should be individualized. Airway clearance therapies should be performed daily as maintenance treatment, with increased frequency during pulmonary exacerbations. ${ }^{95}$ No single airway clearance modality has been shown to be better than another.96,97 There are no evidence-based data to clearly demonstrate that the order of therapy for aerosol medications and chest physical therapy makes a clinical difference.

Rehydrating therapy is performed by inhalation of osmotically active aerosols (eg, 7\% hypertonic saline solution or mannitol). ${ }^{98}$ Clinical studies of $7 \%$ hypertonic saline in $\mathrm{CF}$ have reported sustained increases in mucociliary clearance, improved $\mathrm{FEV}_{1}$, and reduced frequency of exacerbations. ${ }^{99}$ Mannitol is a nonabsorbable sugar alcohol, which provides an osmotic gradient on the airway surface leading to rehydration. ${ }^{100}$ Both agents are irritants and are best considered as expectorants, ${ }^{102}$ which require pretreatment with a bronchodilator. Dornase alfa, an inhaled mucolytic, depolymerizes the neutrophil-derived DNA and filamentous actin (F-actin) of purulent CF sputum. ${ }^{101}$ Dornase alfa should not be mixed with $7 \%$ hypertonic saline solution. Although many different medications have been used in patients with $\mathrm{CF}$, including ambroxal, carbocysteine, and guaifenesin, none of these are proven to be beneficial. Inhaled $N$-acetylcysteine has not shown mucinreducing activity, probably because mucin in the $\mathrm{CF}$ air- 
way is largely degraded by bacterial and endogenous proteases. ${ }^{103}$

Inhaled antibiotic therapy is part of standard of care and should be administered as chronic suppressive therapy with either single-agent therapy or alternating therapy with different antibiotics. ${ }^{104}$ Inhaled tobramycin, aztreonam, and colistin are recommended only for patients with $P$. aeruginosa. Azithromycin, a macrolide antibiotic recommended for chronic suppressive therapy in patients with $\mathrm{CF}$ who screen positive for $P$. aeruginosa. ${ }^{104}$ The beneficial effects are likely due to their anti-inflammatory activities. ${ }^{104}$ Inhaled corticosteroids are highly effective against eosinophil inflammation, but they have little effect on neutrophils, which are the predominant cell in the $\mathrm{CF}$ airway.

\section{Atelectasis}

Patients with $\mathrm{CF}$ are known to produce abundant purulent sputum consisting mainly of DNA and cellular debris. A radiologically apparent volume loss in a segment or a lobe of a lung, or sometimes the entire lung, caused by the accumulation of purulent secretions and airway obstruction often coexists with bronchiectasis. ${ }^{105}$ Early in the disease, atelectasis most frequently involves the upper lobes, creating negative intra-pleural pressure, applying traction to already weakened bronchial walls, and dilating the associated bronchus. Atelectasis is treated with airway clearance therapy, bronchodilators, dornase alfa, hydrators (expectorants), and antibiotics.

\section{Airway Hyper-Reactivity}

Bronchodilators are used extensively among individuals with $\mathrm{CF}$. The vast majority of those prescribed $\beta_{2}$ agonists are on short-acting formulations. ${ }^{3}$ Bronchodilators remain the most commonly used medications in patients with $\mathrm{CF}$ despite the lack of solid data to support their routine use. ${ }^{106}$ Establishing the diagnosis of asthma in $\mathrm{CF}$ is challenging given the inconsistency of hyper-responsiveness and bronchial provocation testing in these patients. Further, symptoms of asthma may be absent or difficult to separate from the CF lung disease itself. ${ }^{106}$ Some patients with CF and a family history of asthma may exhibit recurrent acute episodes of shortness of breath that respond to an inhaled $\beta_{2}$ agonist or systemic corticosteroids. ${ }^{107}$ In this setting, inhaled corticosteroids may be reasonable. ${ }^{107}$ It has been suggested that subjective improvement in symptoms or improved sputum production when a bronchodilator is administered before airway clearance therapy may also merit its use in individual patients. ${ }^{107}$

\section{Pulmonary Emergencies in Cystic Fibrosis}

\section{Hemoptysis}

As with other common complications, hemoptysis (ie, coughing up blood from the lungs) is usually associated with older patients and more severe disease. ${ }^{108}$ The amount of blood ranges from blood-streaked sputum (scant) to a large amount (massive). Massive hemoptysis has been defined as $>240 \mathrm{~mL}$ in $24 \mathrm{~h} .{ }^{108}$ Approximately 5\% of all patients with $\mathrm{CF}$ will suffer massive hemoptysis during their lifetime. ${ }^{108}$ Hemoptysis has been reported as a potential adverse event in clinical trials. ${ }^{109}$

The pathogenesis of hemoptysis in CF is incompletely understood. It has been attributed to chronic inflammation and infection with erosion into capillary or arterial walls, such that the pressure within the blood vessel may cause an upsurge of blood into the airways. ${ }^{108}$ Mild hemoptysis may be due to injury of small vessels such as capillaries or even arterioles. Because of the large pressure gradient from the systemic bronchial artery circulation to the pulmonary circulation, bleeding from the larger and more numerous bronchial arteries can often be massive.

Increasing age, severe impairment of lung function, and $P$. aeruginosa infection have been identified as the most significant risk factors for the development of massive hemoptysis. ${ }^{108}$ However, nearly $25 \%$ of massive hemoptysis events occur in patients $<18$ y old, and $10 \%$ of episodes occur in patients with normal lung function. ${ }^{108}$ Other risk factors include the presence of endobronchial infection with $S$. aureus ${ }^{108}$ and CF-related conditions such as vitamin $\mathrm{K}$ deficiency with associated clotting disorder, liver cirrhosis with complicating hypersplenism, and diabetes.

Patients with more than scant hemoptysis should be admitted to the hospital and treated with antibiotics even if there are no other manifestations of a pulmonary exacerbation. ${ }^{112}$ Nonsteroidal anti-inflammatory drugs should be withheld, but other regular treatments, including nebulized therapies, airway clearance, and noninvasive ventilation, should be continued. ${ }^{112}$

Massive hemoptysis is a life-threatening medical emergency because patients are at risk of death from asphyxiation and hypovolemia, and all patients with massive hemoptysis should be admitted to the hospital. ${ }^{110,111}$ Airway protection, volume resuscitation, and supplemental oxygen must be implemented before definitive therapy may be given. ${ }^{110,111}$ Because massive hemoptysis is frequently associated with $S$. aureus infection, patients should be started with antibiotics against $S$. aureus, and airway clearance techniques should be stopped for patients due to the risk of impeding clot formation. ${ }^{111,112}$ Nonsteroidal anti-inflammatory drugs, inhaled bronchodilators, and hypertonic saline should be withheld. Pulmonary bleeding may be wors- 


\section{CF OverVIEW}

ened by coagulopathy secondary to low vitamin $\mathrm{K}$ or underlying CF-related liver disease. Most patients will do well with treatment, and bleeding will generally resolve without complications. However, there is a greater morbidity and mortality in patients with $\mathrm{CF}$ who experience massive hemoptysis. ${ }^{111,112}$

For patients with life-threatening bleeding or persistent bleeding despite other therapies, selective bronchial artery embolization is recommended. Overall, bronchial artery embolization is successful in terminating bleeding. However, hemoptysis may recur and repeat embolization may be necessary. ${ }^{110-112}$ Although rare, spinal artery embolization is a potential complication. ${ }^{110-112}$ Surgery (most commonly lobectomy) is recommended as the last therapeutic resort in patients with $\mathrm{CF}$ with ongoing bleeding despite bronchial artery embolization. ${ }^{111,112}$ Lung transplantation should also be considered for patients with recurrent massive hemoptysis who are at risk of death during these episodes.

\section{Pneumothorax}

Approximately 3-4\% of individuals with CF will experience a pneumothorax during their lifetime. ${ }^{111,112}$ This complication occurs more commonly in patients with advanced disease and it presents with chest pain and shortness of breath. There are some anatomical and functional risk factors. Cysts, blebs (1-2 cm in diameter), and bullae $(>2 \mathrm{~cm}$ in diameter) are all identified in the lungs of $\mathrm{CF}$ patients. ${ }^{113}$ These areas are susceptible to distention as a result of air trapping secondary to small airway obstruction and high residual volumes. ${ }^{113}$ Other risk factors include severe air-flow obstruction and allergic bronchopulmonary aspergillosis.

A chest radiograph is often sufficient to establish the diagnosis of pneumothorax; however, diagnosing pneumothorax may be difficult in certain patients with advanced $\mathrm{CF}$ lung disease. Pleural adhesions are common among such patients, and, thus, any associated lung collapse is frequently non-uniform. Therefore, the use of a computed tomography (CT) chest scan is justified to aid in the evaluation and management of these patients. ${ }^{113}$

The treatment of pneumothorax depends on its size and patient's clinical stability. A patient with a small pneumothorax who is otherwise clinically stable may be closely observed in the out-patient setting. Factors to be considered when determining whether to hospitalize include the reliability of the patient and the family, and the ease of access to health care if the pneumothorax worsens. A patient with a large pneumothorax should always be treated with a chest tube. ${ }^{113}$ Additional measures to reduce the risk of deterioration include appropriate analgesia, adequate hydration, intravenous antibiotics, airway clearance, inhalation therapies, and early mobilization under the supervision of respiratory therapists. ${ }^{113}$

The risk of pneumothorax recurrence in patients with $\mathrm{CF}$ is high (estimated 50-90\%), and it is likely to remain high for a period of 12 months after resolution. ${ }^{113}$ Published guidelines do not recommend pleurodesis for the first occurrence of a pneumothorax, regardless of whether it is large or small. ${ }^{111,112}$ However, patients with recurrent large pneumothorax should undergo pleurodesis to prevent recurrence and its associated morbidity (eg, pain, dyspnea). Pleurodesis may also be considered for those patients with persistent air leak (ie, continuous bubbling through the chest tube with or without re-expansion of the collapsed lung at $48 \mathrm{~h}$ ). The preferred method is surgical pleurodesis via video-assisted thoracoscopy or through a limited or full thoracotomy. ${ }^{111,112}$ Pleurodesis is no longer an absolute contraindication for lung transplantation.

\section{Respiratory Failure}

The natural course of CF lung disease is a progressive decline in lung function, leading to impaired gas exchange and increased work of breathing, progressing to an inability to maintain normal arterial oxygenation, and eventually resulting in respiratory failure. ${ }^{114}$ Patients with $\mathrm{CF}$ often have sleep-related issues due to their decreasing baseline arterial oxygen saturation proportionate with the severity of the lung disease. ${ }^{115}$ During the REM sleep stage, when the minute ventilation is lowest and lung volumes are reduced, nocturnal hypoxemia occurs; this is found mostly in patients with advanced lung disease, but it may also be seen in patients with milder disease. Hypoxemia is not usually associated with arousal from sleep and thus may be unrecognized. ${ }^{115}$ As the lung disease progresses, hypercapnia eventually develops. Patients with hypercapnic respiratory failure benefit from noninvasive ventilation, which may be delivered nasally or through a face mask or mouthpiece. It may be applied continuously or with different inspiratory and expiratory pressures (bi-level positive airway pressure). Noninvasive ventilation is now considered a bridge for patients awaiting lung transplantation, and it may improve quality of life by reducing dyspnea and chest pain. ${ }^{114,116}$

Chronic alveolar hypoxia, progressive destruction of pulmonary vascular structure, and persistent increase in cardiac output may result in pulmonary hypertension and cor pulmonale. ${ }^{116}$ Pulmonary hypertension correlates with the degree of hypoxemia. ${ }^{113}$ Pulmonary hypertension is common in individuals with advanced CF-related lung disease. The goal of therapy for early pulmonary hypertension in $\mathrm{CF}$ is to correct hypoxemia and lower the elevated pulmonary artery pressures. Supplemental oxygen and intensive treatment of the pulmonary disease may help achieve this goal. ${ }^{116}$ Diuretics may be indicated in patients with 
right-sided heart failure. Phosphodiestearase-5 inhibitors like sildenafil may be useful in some patients. ${ }^{116}$ If the patient has been evaluated for lung transplantation, there have been favorable experiences with transplantation for patients on assisted ventilation. ${ }^{117}$

\section{Diagnostic Imaging}

Progressive lung disease is the life-limiting factor in CF. Capturing the severity of CF lung disease and monitoring it over time are important in guiding clinical care and in measuring outcomes in clinical trials. Imaging offers information on the regional distribution of CF lung disease, so longitudinal imaging is recommended for disease tracking in clinical practice. Chest radiography, CT, and magnetic resonance imaging (MRI) are now available as common imaging techniques. ${ }^{118,119}$

Chest radiography has been regularly used in CF clinics and often on a yearly basis. Although chest radiographs may have some value in monitoring patients longitudinally, their sensitivity on an individual basis is limited because early disease abnormalities such as air trapping and early bronchiectasis are not well captured with conventional radiography. ${ }^{119} \mathrm{~A}$ posterior-anterior and a lateral view are recommended in adolescents and adults. In young children, the lateral view does not reveal relevant additional information and may be omitted. ${ }^{120}$

CT defines early abnormalities and progression of structural changes in the absence of declining $\mathrm{FEV}_{1}$. It provides the highest morphological detail. ${ }^{121}$ Non-contrast-enhanced multi-detector CT data can be post-processed with special software for a detailed measurement of airway dimensions and bronchiectasis, which can potentially allow a more precise scoring of disease severity. However, although the radiation dose has been reduced and limited slice sampling has been suggested to restrict radiation exposure, ${ }^{121}$ it is still controversial to include routine CT imaging in clinical care of patients with $\mathrm{CF}$, which is typically a young population with high sensitivity to ionizing radiation and lifetime dosage accumulation. Moreover, for young children unable to cooperate, CT scanning may require sedation.

MRI is an option as a radiation-free diagnostic modality. Although MRI usually provides poor visualization of the lung, there are now multiple MRI-based imaging techniques to assess the lung both structurally and functionally. ${ }^{122}$ The spatial resolution of structural MRI has greatly improved, and the introduction of ultrashort echo time sequences has further enhanced image quality. ${ }^{123}$ MRI may detect early CF lung disease leading to both structural and functional abnormalities. Structural MRI may not be as effective as CT in outlining bronchiectasis, at least in its early stages. However, mucus plugging is adequately captured on MRI. Functional MRI, such as ventilation MRI using tracer gases, can be combined with structural MRI and has a potential advantage over pulmonary function tests because it can better define regional abnormalities, which are characteristic of early CF lung disease.

Hyperpolarized helium-3 and xenon-129 are inhaled contrast agents for MRI to image ventilation and gas exchange. ${ }^{124}$ MRI with hyperpolarized gas does not involve ionizing radiation. When a patient inhales a hyperpolarized gas, well ventilated areas of the lung appear bright on MRI, whereas areas of the lung that are poorly ventilated appear dark on MRI. ${ }^{124}$ Patient with CF and normal spirometry have been found to have ventilation defects on hyperpolarized MRI. ${ }^{125}$ The high cost of the procedure and the need for sedation or anesthesia for young children has been an area of concern.

\section{Pulmonary Function Testing}

Pulmonary function tests are routinely performed in the clinical management of patients with $\mathrm{CF}$, and they are being increasingly applied in infants and preschool children. They are useful to determine the severity of lung disease, to gauge response to therapy, and to monitor disease progression.

Spirometry is the most commonly performed pulmonary function test in the clinical setting. A systematic review reported that $P$. aeruginosa infection and pancreatic insufficiency were most commonly associated with lower baseline and more rapid declines in percent of predicted $\mathrm{FEV}_{1} \cdot{ }^{126} \mathrm{~A}$ reduced FVC in spirometry cannot differentiate the loss of lung volume due to restrictive lung disease versus the reduction in FVC that occurs secondary to airway obstruction; thus measurement of static lung volume is required. Plethysmographic lung volumes, which are the accepted standard for identifying restrictive lung disease, are frequently included in the annual evaluation of $\mathrm{CF}$ patients, although children $<6$ y old may be unable to perform satisfactory maneuvers against the closed shutter. Under these circumstances, use of gas dilution or washout techniques to measure functional residual capacity may be considered, although this may underestimate the extent of air trapping.

Spirometry is useful for determining the severity of $\mathrm{CF}$ lung disease, tracking its progression, and guiding treatment, but "normal" spirometry results do not necessarily mean normal lung function. Multiple breath washout testing has emerged as a promising measure of early obstructive disease in patients with CF. ${ }^{127}$ Multiple breath washout measures ventilation inhomogeneity of the lung via diffusion of an inert gas, such as nitrogen $\left(\mathrm{N}_{2}\right)$ or sulfur hexafluoride $\left(\mathrm{SF}_{6}\right)$, during tidal breathing; this test does not require forced expiratory maneuvers. ${ }^{127}$

As a diffusion measure, multiple breath washout is primarily influenced by the small peripheral airways (bronchioles), where early obstructive disease characteristically 
occurs, whereas flows and volumes measured with spirometry are driven primarily by airway resistance, the majority of which occurs in larger airways (ie, $\mathrm{FEV}_{1}$ likely reflects disease in larger airways). ${ }^{127}$ The lung clearance index, which is a pulmonary function measurement that is becoming increasingly used in patients with $\mathrm{CF}$, has been shown to be more sensitive than $\mathrm{FEV}_{1}$ for identifying lung disease in children with $\mathrm{CF}^{123}$ and more sensitive than chest $\mathrm{CT}$ in detecting early $\mathrm{CF}$ lung disease. ${ }^{128}$ The lung clearance index holds great promise as a sensitive measure of early lung disease in $\mathrm{CF}$ and is being used as an outcome measure in clinical trials.

\section{Infection Control}

P. aeruginosa, Burkholderia species, A. xylosoxidans, and MRSA are the organisms most commonly transmitted in patients with CF. The primary routes of pathogen transmission include direct contact (person to person), indirect contact with infectious secretions via a contaminated object, and infectious droplets containing pathogens traveling 3-6 feet from an infected person to a susceptible person by way of a cough, sneeze, or respiratory procedure. ${ }^{129}$ It is presumed that all patients with CF have contagious pathogens in their respiratory tract secretions. Accordingly, patients and their families should be educated regarding infection prevention and control strategies on a regular basis. The most important measures to prevent the spread of infection are handwashing, the use of masks in health care facilities, and avoidance of in-person socialization. ${ }^{129}$ For example, at indoor events, only one person with CF may be present; at outdoor events, patients with $\mathrm{CF}$ are required to maintain a distance of at least 6 feet from one another. ${ }^{129}$

The handling and care of the nebulizers and airway clearance devices are extremely important. ${ }^{130}$ Recommendations for nebulizer care include cleaning, disinfecting, rinsing, and air-drying all parts of the device between uses. ${ }^{131}$ Cold disinfection may be achieved by using $70 \%$ isopropyl alcohol or $3 \%$ hydrogen peroxide; heated disinfection includes boiling water and microwave or dishwasher use. ${ }^{131}$ Acetic acid (vinegar) is not effective against $S$. aureus, so it should not be used as a disinfectant. ${ }^{131}$ After cold disinfection, equipment should be rinsed with sterile water because tap water or distilled water may harbor pathogenic organisms. For more information, the reader is referred to a recent publication on infection prevention and control guidelines for the growing number of respiratory devices. ${ }^{132}$

\section{Lung Transplantation}

Lung transplantation for CF has evolved over the last decades, leading to improved outcomes, and transplantation will remain an important treatment option for advanced-stage dis- ease. ${ }^{133}$ Despite comorbidities, including infections with multi-drug resistant organisms, diabetes, and gastrointestinal complications, patients with CF benefit from lung transplantation in terms of survival. ${ }^{134}$ Nonetheless, many individuals with CF die from respiratory failure without referral for lung transplantation. ${ }^{135}$ The number of lung transplants for adults with CF has increased, from a few in the late 1980s to $>250$ in 2016. ${ }^{3}$ Post-transplant survival is highly variable, ranging from a few days or weeks to $>20$ years. The International Society for Heart and Lung Transplantation reports that the median survival from lung transplantation for patients with $\mathrm{CF}$ is $9.5 \mathrm{y} .{ }^{134}$

Identifying individuals most likely to benefit from lung transplantation is a challenge and donor lungs remain a limited resource. Another challenge is the optimal timing of referral for lung transplantation evaluation. Shortterm survival for pretransplant patients is variable and unpredictable. Survival after predicted $\mathrm{FEV}_{1}<30 \%$ during periods of clinical stability has been reported to be 6.6 y. ${ }^{135}$ A retrospective review of CF Foundation Patient Registry data of individuals with a stable $\mathrm{FEV}_{1}<30 \%$ (ie, a key criterion for transplant referral) ${ }^{136}$ revealed that almost $35 \%$ were not referred despite having severe lung impairment. These data highlight improvements in survival with advanced disease and challenges with predicting survival versus referring a patient for transplant.

Lung transplantation referral should be initiated for individuals with advanced but not end-stage lung disease. One important objective is to improve education and decision-making around transplant candidacy to ensure that vital opportunities are not missed due to misinformation and non-referral. ${ }^{137}$ The Cystic Fibrosis Foundation recently published Cystic Fibrosis Lung Transplant Referral Consensus Guidelines. ${ }^{138}$ While many individuals who meet these Guidelines' criteria for referral will not need to be put on the waiting list, it is important to note that referral does not necessarily lead to a full evaluation or listing, but instead gives individuals with $\mathrm{CF}$, their families, and the CF care team access to the transplant-specific expertise of lung transplantation centers.

For individuals with $\mathrm{CF}<18$ y old, the Cystic Fibrosis Foundation recommends lung transplant referral no later than when:

- $\mathrm{FEV}_{1}<50 \%$ predicted and rapidly declining $(>20 \%$ relative decline in $\mathrm{FEV}_{1}$ within 12 months) OR

- $\mathrm{FEV}_{1}<40 \%$ predicted with markers of shortened survival OR

- $\mathrm{FEV}_{1}<30 \%$ predicted.

For individuals with $\mathrm{CF} \leq 18$ y old, the Cystic Fibrosis Foundation recommends lung transplant referral no later than when: 
- $\mathrm{FEV}_{1}<50 \%$ predicted and rapidly declining $(>20 \%$ relative decline in $\mathrm{FEV}_{1}$ within 12 months) OR

- $\mathrm{FEV}_{1}<50 \%$ predicted with markers of shortened survival OR

- $\mathrm{FEV}_{1}<40 \%$ predicted.

For individuals with $\mathrm{CF}$ and $\mathrm{FEV}_{1}<40 \%$ predicted, the Cystic Fibrosis Foundation recommends an annual 6-min walk test, assessment of need for supplemental oxygen, and venous blood gas to screen for markers of severe disease that may warrant transplant referral. For individuals with $\mathrm{CF}$ who are $\geq 18$ y old with $\mathrm{FEV}_{1}<40 \%$ predicted, a baseline echocardiogram is recommended to screen for pulmonary hypertension.

The Cystic Fibrosis Foundation recommends lung transplant referral, regardless of $\mathrm{FEV}_{1}$, when there are markers of shortened survival, including:

- 6-min walk distance $<400$ m OR

- Hypoxemia $\left(\mathrm{S}_{\mathrm{pO}_{2}}<88 \%\right.$ or $\mathrm{P}_{\mathrm{aO}_{2}}<55 \mathrm{~mm} \mathrm{Hg}$ at rest or with exertion at sea level) OR

- Hypercarbia $\left(\mathrm{P}_{\mathrm{aCO}_{2}}>50 \mathrm{~mm} \mathrm{Hg}\right.$, confirmed with arterial blood gas) $\mathrm{OR}$

- Pulmonary hypertension (systolic pressure $>50 \mathrm{~mm} \mathrm{Hg}$ on echocardiogram or evidence of right ventricular dysfunction in the absence of a tricuspid regurgitant jet).

The Cystic Fibrosis Foundation recommends lung transplant referral for adults with $\mathrm{CF}$ with a body mass index $<18 \mathrm{~kg} / \mathrm{m}^{2}$ and $\mathrm{FEV}_{1}<40 \%$ predicted while concurrently working to improve nutritional status. The Cystic Fibrosis Foundation further recommends referral for individuals with $\mathrm{CF}$ with:

- $\mathrm{FEV}_{1}<40 \%$ predicted and $>2$ exacerbations per year requiring intravenous antibiotics or 1 exacerbation requiring positive-pressure ventilation regardless of $\mathrm{FEV}_{1}$.

- $\mathrm{FEV}_{1}<40 \%$ predicted and massive hemoptysis ( $>240 \mathrm{~mL}$ ) requiring ICU admission or bronchial artery embolization.

- $\mathrm{FEV}_{1}<40 \%$ predicted and pneumothorax.

- Short stature (height $<162 \mathrm{~cm}$ ), even when other thresholds have not been met.

- For females with CF, especially those who are younger, even when other thresholds have not been met.

The Cystic Fibrosis Foundation recommends consultation with local and geographically distant lung transplant centers for individuals with microorganisms that may pose a risk for lung transplantation (eg, B. cepacia complex, nontuberculous Mycobacterium, certain molds such as Scedosporium). Patients with CF should consult at least 2 trans- plant centers, one of which should have experience addressing the individual's potential contraindications to transplantation, before determining that an individual is not a transplant candidate. ${ }^{138}$

\section{New Treatment Strategies}

As discussed above, CF is caused by gene mutations that result in an abnormal $C F T R$ protein on the apical surface of epithelial cells. CFTR modulators are a novel class of drugs that directly target the abnormal CFTR protein molecular defect. These modulators include potentiators that result in improved activity of the channel, correctors that help the protein traffic to the cell surface properly, and read-through agents that target the ribosome or other aspects of the translational machinery to restore full-length $C F T R$ by suppression of premature termination codons, thereby reestablishing CFTR activity.

Clinical benefits of potentiators such as ivacaftor have been reported in patients with the p.G551Ddel mutation, which has an incidence of $4-5 \%$ in the United States but higher incidence in the United Kingdom and Ireland (ie, the "Celtic" mutation); the p.G551Ddel mutation is termed a gating mutation because it impairs the regulated opening (ie, reduced channel-open probability) of the ion channel that is formed by the CFTR protein. Ivacaftor may also benefit other closely related gating mutations. Ivacaftor treatment has been described to improve pulmonary function and patient-reported respiratory symptoms, promote weight gain, and correct the sweat chloride defect. ${ }^{139} \mathrm{~Pa}-$ tients who receive ivacaftor still require other symptombased treatments to control the disease, however, including pancreatic-enzyme replacement, inhaled hydrators and mucolytic agents, and antibiotic therapies. Ivacaftor has been approved for the treatment of children with $\mathrm{CF}$ as young as 6 months of age who have at least one mutation in the CFTR gene.

However, the main therapeutic target has been the p.F508 del - the most common mutation. In this mutation, not only does the CFTR protein fold incorrectly and have impaired trafficking to the epithelial surface, but the CFTR channel is open for a shorter time. Ivacaftor may improve the open-channel probability of this protein. Lumacaftor, a CFTR corrector, improves the processing and trafficking of the mutant CFTR and prolongs its residence at the cell surface, but it has no effect on channel opening. Studies of the effect of this combination in patients with CF homozygous for the p.F508del mutation reported relatively modest improvements in lung function, nutrition, and pulmonary exacerbations. ${ }^{140}$ The combination of ivacaftor and lumacaftor was approved by the FDA for CF patients $\geq 2 \mathrm{y}$ old and homozygous for the p.F508del mutation.

The combination of tezacaftor (a corrector) and ivacaftor (a potentiator) in patients with $\mathrm{CF}$ homozygous for 
the p.F508del mutation ${ }^{141}$ and for patients with CF heterozygous for the p.F508del mutation and a second residual-function mutation underwent clinical testing. ${ }^{142}$ This combination (Symdeko) improved lung function $\left(\mathrm{FEV}_{1}\right)$ in patients with $\mathrm{CF}$ who have the most common genotype, an effect similar to that of combined lumacaftorivacaftor, but with an improved side effect and drug-todrug interaction profile. The combination also improved lung function in patients with a p.F508del mutation and a residual-function mutation to a degree similar to that of ivacaftor alone.

These trials indicated that although CFTR modulator therapies had measurable beneficial effects on some aspects of the disease, there was still an unmet need for truly effective new therapies to be developed for all individuals with CF who have the most common CFTR mutation. ${ }^{143}$

Thus, a triple drug therapy was developed for patients who fail to respond or respond poorly to the above already approved CF therapies. The recently published results from two Phase 3 clinical trials ${ }^{144,145}$ document impressive improvements in FEV1, a strong predictor of clinical status in cystic fibrosis, patient-reported respiratory symptoms, and sweat chloride concentration, a marker of CFTR activity from elexacaftor plus tezacaffor plus ivacaftor (Trikafta) in patients 12 years of age or older with cystic fibrosis and at least one copy of the p.F508del mutation. No worrisome safety signals were reported. Given the recent approval of this drug by the FDA, these findings imply that it may soon be possible to offer safe and effective molecularly targeted therapies to $90 \%$ of persons with cystic fibrosis. ${ }^{146}$

\section{Summary}

Although significant advances have prolonged the average life expectancy for patients with $\mathrm{CF}$, and more than half of the CF patient population is now in the adult age range, there remains no cure for this disease. Lung disease progression will still lead to respiratory failure in the majority of these patients. Early referral of patients with advanced disease for lung transplantation is important for their education and the modification of risk factors associated with worse outcomes.

A better understanding of the link between a lack of CFTR function and CF lung involvement has transformed the treatment for people with CF. The last decade has witnessed a new era in the development of drugs focused on the basic defect in the disease. The research field remains very active, offering hope that further novel therapies, with perhaps greater potential, will become available in the near future. However, regardless of what health care providers do and what therapeutic advances occur, suboptimal adherence to CF therapies will negatively affect the clinical and economic burden of this disease. Higher treat- ment adherence is a major determinant to reduce disease burden and improve patient outcomes. The ongoing relationships between patients with $\mathrm{CF}$, their families, clinical research teams, national and international organizations, and the pharmaceutical industry will continue to make progress in further advancing therapies for people with this disease. In resource-poor countries, costs of medications fall heavily upon the family and therefore, cost and affordability are major hurdles. The cost of some medicines must come down: medicines can only improve the quality and quantity of life if they are affordable for those who need them.

\section{ACKNOWLEDGMENTS}

I thank Drs Robert Giusti (New York University, NYC, NY), Henry A Wojtczak (Naval Medical Center, San Diego, CA), and Olga M Herren (National Institutes of Health, Bethesda, MD) for their careful reading and helpful comments to an earlier version of the manuscript; Ms Melissa L Turcios, Esq. for her editorial assistance; Christopher Hoenig (Medical Staff Communications), Robert Wood Johnson (University Hospital, New Brunswick, NJ) for his help in obtaining the images, and Ms Lawren Wilkins, Medical Librarian for the literature search.

\section{REFERENCES}

1. Stoltz DA, Meyerholz DK, Welsh MJ. Origins of cystic fibrosis lung disease. N Engl J Med 2015;372:351-362.

2. Rubin BK. Cystic fibrosis: myths, mistakes, and dogma. Paediatr Respir Rev 2014;15:113-116.

3. Cystic Fibrosis Foundation Patient Registry Report 2016. Bethesda, MD: Cystic Fibrosis Foundation, 2017.

4. Cohen-Cymberknoh M, Shoseyov D, Kerem E. Managing cystic fibrosis: strategies that increase life expectancy and improve quality of life. Am J Respir Crit Care Med 2011;183(11):1463-71.

5. Ahmed NN and Durie PR. Nonpulmonary manifestations of cystic fibrosis. In: Wilmott, Boat, Bush, Chernick, Deterding, Ratjen, editors. Disorders of the respiratory tract in children. Philadelphia: Elsevier; 2012:781-795.

6. Collins S. Nutritional management of cystic fibrosis: an update for the 21st century. Paediatr Respir Rev 2018;26:4-6.

7. Faro A, Michelson PH, Ferkol, TW: Pulmonary disease in cystic fibrosis. In: Wilmott, Boat, Bush, Chernick, Deterding, Ratjen, editors. Disorders of the respiratory tract in children. Philadelphia: Elsevier; 2012:770-780.

8. Farrell PM, White TB, Ren CL, Hempstead SE, Accurso F, Derichs $\mathrm{N}$, et al: Diagnosis of cystic fibrosis: consensus guidelines from the Cystic Fibrosis Foundation. J Pediatr 2017;181(Suppl 4):S4-S15.

9. Strong TV, Smit LS, Turpin SV, Cole JL, Tom Hon C, Markiewicz $\mathrm{D}$, et al. Cystic fibrosis gene mutation in two sisters with mild disease and normal sweat electrolyte levels. N Engl J Med 1991; 325(23):1630-1634.

10. Feldmann D, Couderc R, Audrezet MP, Ferec C, Bienvenu T, Desgeorges $\mathrm{M}$, et al. CFTR genotypes in patients with normal or borderline sweat chloride levels. Hum Mut 2003;22(4):340.

11. Cirilli N, Braggion C, Mergni G, Polizzi AM, Padoan R, Sirianni S, et al. May the new suggested lower borderline limit of sweat chloride impact the diagnostic process for cystic fibrosis? J Pediatr 2018;194:261-262.

12. Sosnay, PR, White TB, Farrell PM, Ren CL, Derichs N, et al. Diagnosis of cystic fibrosis in nonscreened populations. J Pediatr 2017;181(Suppl 4):S52-S57. 
13. Boyle M, De Boeck K. A new era in the treatment of cystic fibrosis: correction of the underlying CFTR defect. Lancet Respir Med 2013; 1:158-163.

14. Kerem E, Corey M, Kerem BS, Rommens J, Markiewicz D, Levison $\mathrm{H}$, et al. The relation between genotype and phenotype in cystic fibrosis-analysis of the most common mutation (delta F508). N Engl J Med 1990;323(22):1517-1522.

15. Vanscoy LL, Blackman SM, Collaco JM, Bowers A, Lai T, Naughton $\mathrm{K}$, et al. Heritability of lung disease severity in cystic fibrosis. Am J Respir Crit Care Med 2007;175(10):1036-1043.

16. Knowles MR, Boucher RC. Mucus clearance as a primary innate defense mechanism for mammalian airways. J Clin Invest 2002; 109(5):571-577.

17. Button B, Cai LH, Ehre C, Kesimer M, Hill DB, Sheehan JK, et al. A periciliary brush promotes the lung health by separating the mucus layer from airway epithelia. Science 2012;337:937-941.

18. Boucher RC. Muco-obstructive lung diseases. N Engl J Med 2019; 380:1941-1953.

19. Rowe SM, Miller S, Sorscher EJ. Cystic fibrosis. N Engl J Med 2005;352:1992-2001.

20. Kesimer M, Ford AA, Ceppe A, Radicioni G, Cao R, Davis CW, et al. Airway mucin concentration as a marker of chronic bronchitis. N Engl J Med 2017;377:911-922.

21. Worlitzsch D, Tarran R, Ulrich M, Schwab U, Cekici A, Meyer $\mathrm{KC}$, et al. Effects of reduced mucus oxygen concentration in airway Pseudomonas infections of cystic fibrosis patients. J Clin Invest 2002;109(3):317-325.

22. Chalmers JD, Moffitt KL, Suarez-Cuartin G, Sibila O, Finch S, Furrie E, et al. Neutrophil elastase activity is associated with exacerbations and lung function decline in bronchiectasis. Am J Respir Crit Care Med 2017;195:1384-1393.

23. Sly PD, Gangell CL, Chen L, Ware RS, Ranganathan S, Mott LS, et al. Risk factors for bronchiectasis in children with cystic fibrosis. N Engl J Med 2013;368:1963-70.

24. Chmiel JF, Aksamit TR, Chotirmall SH, Dasenbrook EC, Elborn JS, LiPuma JJ, et al. Antibiotic management of lung infections in cystic fibrosis. I. The microbiome, methicillin-resistant Staphylococcus aureus, gram-negative bacteria, and multiple infections. Ann Am Thorac Soc 2014;11(7):1120-1129.

25. Lipuma JJ. The changing microbial epidemiology in cystic fibrosis. Clin Microbiol Rev 2010;23:(2):299-323.

26. Cystic Fibrosis Foundation Patient Registry 2017. Bethesda, MD: Cystic Fibrosis Foundation, 2018.

27. Heirali AA, Workentine ML, Acosta N, Poonja A, Storey DG, Somayaji R, et al. The effects of inhaled aztreonam on the cystic fibrosis lung microbiome. Microbiome 2017;5(1):51.

28. Emerson J, Rosenfeld M, McNamara S, Ramsey B, Gibson RL. Pseudomonas aeruginosa and other predictors of mortality and morbidity in young children with cystic fibrosis. Pediatr Pulmonol 2002; 34(2):91-100.

29. Douglas TA, Brennan G, Gard L, Berry C, Gangell C, Stick SM, et al. Acquisition and eradication of $P$. aeruginosa in young children with cystic fibrosis. Eur Respir J 2009;33(2):305-311.

30. Treggiari MM, Retsch-Bogart G, Mayer-Hamblett N, Khan U, Kulich M, Kronmal R, et al. Comparative efficacy and safety of 4 randomized regimens to treat early Pseudomonas aeruginosa infection in children with cystic fibrosis. Arch Pediatr Adolesc Med 2011;165(9):847-856.

31. Rosenfeld M. Pseudomonas aeruginosa eradication. Commentary. eCystic Fibrosis Rev 2014;4(5).

32. Ratjen F, Munck A, Kho P, Angyalosi G, ELITE Study Group. Treatment of early Pseudomonas aeruginosa infection in patients with cystic fibrosis: the ELITE trial. Thorax 2010;65(4):286-291.
33. Blanchard AC, Horton E, Stanojevic S, Taylor L, Waters V, Ratjen F. Effectiveness of a stepwise Pseudomonas aeruginosa eradication protocol in children with cystic fibrosis. J Cyst Fibros 2017;16(3): 395-400.

34. Vidya P, Smith L, Beaudoin T, Yau YC, Clark S, Coburn B, et al. Chronic infection phenotypes of Pseudomonas aeruginosa are associated with failure of eradication in children with cystic fibrosis. Eur J Clin Microbiol Infect Dis 2016;35:67-74.

35. Zemanick ET, Emerson J, Thompson V, McNamara S, Morgan W, Gibson RL, Rosenfeld M; EPIC Study Group. Clinical outcomes after initial Pseudomonas acquisition in cystic fibrosis. Pediatr Pulmonol 2015;50:42-48.

36. LiPuma JJ. Understanding the microbiology of the CF lung. eCystic Fibrosis Rev 2016;6(3).

37. Hector A, Kirn T, Ralhan A, Graepler-Mainka U, Berenbrinker S, Riethmueller J, et al. Microbial colonization and lung function in adolescents with cystic fibrosis. J Cyst Fibros 2016;15:340-349.

38. Hoffman L. P. aeruginosa and S. aureus: a love-hate relationship. Pediatr Pulmonol 2017;52(Suppl 47):168.

39. Caverly LJ, Zhao J, LiPuma JJ. Cystic fibrosis lung microbiome: opportunities to reconsider management of airway infection. Pediatr Pulmonol 2015;50(Suppl 40):S31-S38.

40. Dasenbrook EC, Checkley W, Merlo CA, Konstan MW, Lechtzin N, Boyle MP. Association between respiratory tract methicillinresistant Staphylococcus aureus and survival in cystic fibrosis. JAMA 2010;303:2386-2392.

41. Dasenbrook EC. Update on methicillin-resistant Staphylococcus aureus in cystic fibrosis. Curr Opin Pulm Med 2011;17:437-441.

42. Vanderhelst E, De Meirleir L, Verbanck S, Piérard D, Vincken W, Malfroot A. Prevalence and impact on $\mathrm{FEV}_{1}$ decline of chronic methicillin-resistant Staphylococcus aureus (MRSA) colonization in patients with cystic fibrosis. A single-center, case control study of 165 patients. J Cyst Fibros 2012;11:2-7.

43. Lo DK, Hurley MN, Muhlebach MS, Smyth AR. Interventions for the eradication of methicillin-resistant Staphylococcus aureus (MRSA) in people with cystic fibrosis. Cochrane Database Syst Rev 2018;7:CD009650.

44. Stanojevic S, Ratjen F, Stephens D, Lu A, Yau Y, Tullis E, Waters V. Factors influencing the acquisition of Stenotrophomonas maltophilia infection in cystic fibrosis patients. J Cyst Fibros 2013;12: 575-583.

45. Waters V, Atenafu EG, Lu A, Yau Y, Tullis E, Ratjen F. Chronic Stenotrophomonas maltophilia infection and mortality of lung transplantation in cystic fibrosis patients. J Cyst Fibros 2013;12:482486.

46. Lambiase A, Catania MR, Del Pezzo M, Rossano F, Terlizzi V, Sepe A, Raia V. Achromobacter xylosoxidans respiratory tract infection in cystic fibrosis patients. Eur J Clin Microbiol Infect Dis 2011;30(8):973-980.

47. Mahenthiralingam E, Baldwin A, Vandamme P. Burkholderia cepacia complex infection in patients with cystic fibrosis. J Med Microbiol 2002;51(7):533-538.

48. Courtney JM, Dunbar KE, McDowell A, Moore JE, Warke TJ, Stevenson M, Elborn JS. Clinical outcome of Burkholderia cepacia complex infection in cystic fibrosis adults. J Cyst Fibros 2004;3(2): 93-98.

49. Bar-On O, Mussafi H, Mei-Zahav M, Prais D, Steuer G, Stafler P, et al. Increasing nontuberculous mycobacteria infection in cystic fibrosis. J Cyst Fibros 2015;14:53-62.

50. Adjemian J, Olivier KN, Seitz AE, Holland SM, Prevots DR. Prevalence of nontuberculous mycobacterial lung disease in US Medicare beneficiaries. Am J Respir Crit Care Med 2012;185:881-886.

51. Floto RA, Olivier KN, Saiman L, Daley CL, Herrmann JL, Nick JA, et al. US Cystic Fibrosis Foundation and European Cystic Fi- 
brosis Society consensus recommendations for the management of non-tuberculous mycobacteria in individuals with cystic fibrosis. Thorax 2016;71(Suppl 1):i1-i22.

52. Griffith DE, Aksami T, Brown-Elliot BA, Catanzaro A, Daley C, Gordin F, et al. An official ATS/IDSA statement: diagnosis, treatment, and prevention of nontuberculous mycobacteria diseases. Am J Respir Crit Care Med 2007;175(4):367-416.

53. Martiniano SL, Nick JA, Daley CL. Nontuberculous mycobacterial infection in cystic fibrosis. Clin Chest Med 2016;37:83-96.

54. Martiniano SL, Davidson RM, Nick JA. Nontuberculous mycobacteria in cystic fibrosis: updates and the path forward. Pediatr Pulmonol 2017;52(Suppl 48):S29-S36.

55. Ratjen F, Water V. Antibiotic treatment for nontuberculous mycobacteria lung infection in people with cystic fibrosis. Cochrane Database Syst 2016;12;CD010004.

56. Schoen L, Santoro JD, Milla C, Bhargava S. Pulmonary nocardiosis in an immunocompetent patient with cystic fibrosis. Case Rep Pulmonol 2015;2015:984171.

57. Mei-Zahav M, Livnat G, Bentur L, Mussaffi H, Prais D, Stafler P, et al. The spectrum of Nocardia lung disease in cystic fibrosis. Pediatr Infect Dis J 2015;34(8):909-911.

58. Rodriguez-Nava V, Durupt S, Chyderiotis S, Freydière AM, Karsenty J, de Montclos M, et al. A French multicentric study and review of pulmonary Nocardia spp. in cystic fibrosis patients. Med Microbiol Immunol 2015;204(4):493-504.

59. Engel TGP, Erren E, Vanden Driessche KSJ, Melchers WJG, Reijers $\mathrm{MH}$, Merkus P, Verweij PE. Aerosol transmission of Aspergillus fumigatus in cystic fibrosis patients in the Netherlands. Emerg Infect Dis 2019;25(4):797-799.

60. Chotirmall SH, McElvaney NG. Fungi in the cystic fibrosis lung: bystanders or pathogens? Int J Biochem Cell Biol 2014;52:161173.

61. Cystic Fibrosis Foundation Patient Registry Report 2015. Bethesda, MD: Cystic Fibrosis Foundation; 2016.

62. Sabino R, Ferreira JA, Moss RB, Valente J, Veríssimo C, Carolino $\mathrm{E}$, et al. Molecular epidemiology of Aspergillus collected from cystic fibrosis patients. J Cyst Fibros 2015;14(4):474-481.

63. Ziesing S, Suerbaum S, Sedlacek L. Fungal epidemiology and diversity in cystic fibrosis patients over a 5 -year period in a national reference center. Med Mycol 2016;54(8):781-786.

64. Baxter C, Dunn G, Jones AM, Webb K, Gore R, Richardson MD, Denning DW. Novel immunologic classification of aspergillosis in adult cystic fibrosis. J Allergy Clin Immunol 2013;132(3):560-566.

65. Jones AM, Horsley A, and Denning DW. What is the importance of classifying Aspergillus disease in cystic fibrosis patients? Expert Rev Respir Med 2014;8(4):389-392.

66. Stevens DA, Moss, RB, Kurup VP, Knutsen AP, Greenberger P, Judson MA, et al. Allergic bronchopulmonary aspergillosis in cystic fibrosis - state of the art: Cystic Fibrosis Foundation Consensus Conference. Clin Infect Dis 2003;37(Suppl 3):S225-S264.

67. Cohen-Cymberknoh M, Blau H, Shoseyov D, Mei-Zahav M, Efrati O, Armoni S, Kerem E. Intravenous monthly pulse methylprednisolone treatment for ABPA in patients with cystic fibrosis. J Cyst Fibros 2009;8(4):253-257.

68. Elphick HE, Southern KW. Antifungal therapies for allergic bronchopulmonary aspergillosis in people with cystic fibrosis. Cochrane Database Syst Rev 2014;11:CD002204.

69. Jat KR, Walia DK, Khairwa A. Use of anti-IgE treatment for allergic bronchopulmonary aspergillosis in people with cystic fibrosis. Available at: https://www.cochrane.org/CF_use-anti-ige-treatment-allergicbronchopulmonary-aspergillosis. Accessed March 18, 2018.

70. Reece E, Segurado R, Jackson A, McClean S, Renwick J, Greally P. Co-colonisation with Aspergillus fumigatus and Pseudomonas aeruginosa is associated with poorer health in cystic fibrosis patients: an Irish registry analysis. BMC Pulm Med 2017;17(1):70.

71. Mouhajir A, Matray O, Giraud S, Mély L, Marguet C, Sermet-Gaudelus I, et al. Long-term Rasamsonia argillacea complex species colonization revealed by PCR amplification of repetitive DNA sequences in cystic fibrosis patients. J Clin Microbiol 2016;54(11):2804-2812.

72. Pattison SH, Rogers GB, Crockard M, Elborn JS, Tunney MM. Molecular detection of CF lung pathogens: current status and future potential. J Cyst Fibros 2013;12(3):194-205.

73. Liou TG, Adler FR, Fitzsimmons SC, Cahill BC, Hibbs JR, Marshall BC. Predictive 5-year survivorship model of cystic fibrosis. Am J Epidemiol 2001;153:345-352.

74. Mayer-Hamblett N, Rosenfeld M, Emerson J, Goss CH, Aitken ML. Developing cystic fibrosis lung transplant referral criteria using predictors of 2-year mortality. Am J Respir Crit Care Med 2002;166:(12 Pt 1)1550-1555.

75. Konstan MW, Morgan WJ, Butler SM, Pasta DJ, Craib ML, Silva SJ, et al. Risk factors for rate of decline in forced expiratory volume in one second in children and adolescents with cystic fibrosis. J Pediatr 2007;151(2):134-139.

76. Britto MT, Kotagal UR, Hornung RW, Atherton HD, Tsevat J, Wilmott RW. Impact of recent pulmonary exacerbations on quality of life in patients with cystic fibrosis. Chest 2002;121(1):64-72.

77. Baumann U, Stocklossa C, Greiner W, von der Schulenburg JM, von der Hardt $\mathrm{H}$. Cost of care and clinical condition in paediatric cystic fibrosis patients. J Cyst Fibros 2003;2(2):84-90.

78. Waters VJ, Stanojevic S, Sonneveld N, Klingel M, Grasemann H, Yau YC, et al. Factors associated with response to treatment of pulmonary exacerbations in cystic fibrosis patients. J Cyst Fibros 2015;14(6):755-762.

79. Sanders DB, Bittner RC, Rosenfeld M, Hoffman LR, Redding GJ, Goss $\mathrm{CH}$. Failure to recover to baseline pulmonary function after cystic fibrosis pulmonary exacerbation. Am J Respir Crit Care Med 2010;182(5):627-632.

80. VanDevanter DR, Flume PA, Morris N, Konstan MW. Probability of IV antibiotic retreatment within thirty days is associated with duration and location of IV antibiotic treatment for pulmonary exacerbation in cystic fibrosis. J Cyst Fibros 2016;15(6):783-790.

81. Chin M, De Zoysa M, Slinger R, Gaudet E, Vandemheen KL, Chan F, et al. Acute effects of viral respiratory tract infections on sputum bacterial density during CF pulmonary exacerbations. J Cyst Fibros 2015;14(4):482-489.

82. Goss CH, Burns JL. Exacerbations in cystic fibrosis. 1: epidemiology and pathogenesis. Thorax 2007;62(4):360-367.

83. Flume PA, Mogayzel PJ Jr, Robinson KA, Goss CH, Rosenblatt RL, Kuhn RJ, et al. Cystic fibrosis pulmonary guidelines: treatment of pulmonary exacerbations. Am J Respir Crit Care Med 2009;180: 802-808.

84. Stanojevic S, McDonald A, Waters V, MacDonald S, Horton E, Tullis E, Ratjen F. Effect of pulmonary exacerbations treated with oral antibiotics on clinical outcomes in cystic fibrosis. Thorax 2017; 72(4):327-332.

85. Prayle A, Watson A, Fortnum H, Smyth A. Side effects of aminoglycosides on the kidney, ear, and balance in cystic fibrosis. Thorax 2010;65(7):654-658.

86. Smyth A, Lewis S, Bertenshaw C, Choonara I, McGaw J, Watson A, et al. Case-control study of acute renal failure in patients with cystic fibrosis in the UK. Thorax 2008;63(6):532-535.

87. Smyth A, Tan KH, Hyman-Taylor P, Mulheran M, Lewis S, Stableforth D, Prof Knox A, et al. Once versus three-times daily regimens of tobramycin treatment for pulmonary exacerbations of cystic fibrosis -the TOPIC study: a randomized controlled trial. Lancet 2005;365(9459):573-578. 


\section{CF OverVIEW}

88. Prescott WA Jr, Nagel JL. Extended-interval once-daily dosing of aminoglycosides in adult and pediatric patients with cystic fibrosis. Pharmacotherapy 2010;30(1):95-108.

89. Collaco JM, Green DM, Cutting GR, Naughton KM, Mogayzel PJ Jr. Location and duration of treatment of cystic fibrosis Respiratory Exacerbations do not affect outcomes. Am J Respir Crit Care Med 2010;182(9):1137-1143.

90. Roehmel J, Schwarz C, Mehl A, Stock P, Staab D. Hypersensitivity to parenteral antibiotics in patients with cystic fibrosis. J Cyst Fibros 2014;13(2):205-211.

91. Wright MFA, Bush A, Carr S. Hypersensitivity reactions to intravenous antibiotics in cystic fibrosis. Paediatr Respir Rev 2018;27: 9-12.

92. O'Sullivan BP, Flume PA. The clinical approach to lung disease in patients with cystic fibrosis. Semin Respir Crit Care Med 2009;30: 505-513.

93. Main E, Grillo L, Rand S. Airway clearance strategies in cystic fibrosis and non-cystic fibrosis bronchiectasis. Semin Respir Crit Care Med 2015;36(2):251-266.

94. McIlwaine M, Son NL, Chilvers M. Underlying physiological mechanisms of action for airway clearance techniques not requiring devices. Pediatr Pulmonol 2017;52(Suppl 47):140-141.

95. Cystic fibrosis: diagnosis and management. NICE guideline 78 . October 2017. Available at: https://www.nice.org.uk/guidance/ng78. Accessed September 30, 2019.

96. McIlwaine MP, Alarie N, Davidson GF, Lands LC, Ratjen F, Milner R, et al. Long-term multicentre randomised controlled study of high frequency chest wall oscillation versus positive expiratory pressure mask in cystic fibrosis. Thorax 2013;68:746-751.

97. Cystic Fibrosis Trust. Standards of care and good clinical practice for the physiotherapy management of cystic fibrosis, 3rd ed. April 2017. Available at: https://www.cysticfibrosis.org.uk/the-work-wedo/resources-for-cf-professionals/consensus-documents. Accessed September 30, 2019.

98. Donaldson SH, Bennett WD, Zeman KL, Knowles MR, Tarran R, Boucher RC. Mucus clearance and lung function in cystic fibrosis with hypertonic saline. N Engl J Med 2006;354:241-250.

99. Elkins MR, Robinson M, Rose BR, Harbour C, Moriarty CP, Marks $\mathrm{GB}$, et al. A controlled trial of long-term inhaled hypertonic saline in patients with cystic fibrosis. N Engl J Med 2006;354:229-240.

100. Anderson SD, Daviskas E, Brannan JD, Chan HK. Repurposing excipients as active inhalation agents: the mannitol story. Adv Drug Deliv Rev 2018;133:45-56.

101. Konstan MW, Ratjen F. Effect of dornase alfa on inflammation and lung function: potential role in the early treatment of cystic fibrosis J Cyst Fibros 2012;11(2):78-83.

102. Rubin BK. The pharmacologic approach to airway clearance: mucoactive agents. Paediatr Respir Rev 2006;7:S215-S219.

103. Henke MO, Ratjen F. Mucolytics in cystic fibrosis. Paediatr Respir Rev 2007;8:24-29.

104. Mogayzel PJ Jr, Naureckas ET, Robinson KA, Mueller G, Hadjiliadis D, Hoag JB, et al. Cystic fibrosis pulmonary guidelines. Chronic medications for maintenance of lung health. Am J Respir Crit Care Med 2013;187(7):680-689.

105. Stern RC, Boat TF, Orenstein DM, Wood RE, Matthews LW, Doershuk CF. Treatment and prognosis of lobar and segmental atelectasis in cystic fibrosis. Am Rev Respir Dis 1978;118:821-826.

106. Barry PJ, Flume PA. Bronchodilators in cystic fibrosis: a critical analysis. Expert Rev Respir Med 2017;11(1):13-20.

107. Weinberger M. Airway reactivity in patients with CF. Clin Rev Allergy Immunol 2002;23(1):77-85.

108. Flume PA. Review of hemoptysis guidelines. Pediatr Pulmonol 2017;52(Suppl 47):206-207.
109. Thompson V, Mayer-Hamblett N, Kloster M, Bilton D, Flume PA. Hemoptysis is an expected adverse event in cystic fibrosis clinical trials. J Cyst Fibros 2015;14(5):632-638.

110. Flume PA, Yankaskas, JR, Ebeling M, Hulsey T, Clark LL. Massive hemoptysis in cystic fibrosis. Chest 2005;128(2):729-738.

111. Flume PA, Mogayzel PJ Jr, Robinson KA, Rosenblatt RL, Quittell L, Marshall BC, et al. Cystic fibrosis pulmonary guidelines: pulmonary complications: hemoptysis and pneumothorax. Am J Respir Crit Care Med 2010;182:298-306.

112. Smyth AR, Bell SC, Bojcin S, Bryon M, Duff A, Flume P, et al. European Cystic Fibrosis Society standards of care: best practice guidelines. J Cyst Fibros 2014;13(Suppl 1):S23-S42.

113. Lord RW, Jones AM, Webb AK, Barry PJ. Pneumothorax in cystic fibrosis: beyond the guidelines. Paed Respir Rev 2016;20(Suppl): 30-33.

114. Serra A, Polese G, Braggion C, Rossi A. Non-invasive proportional assist and pressure support ventilation in patients with cystic fibrosis and chronic respiratory failure. Thorax 2002;57:50-54.

115. Katz ES. Cystic fibrosis and sleep. Clin Chest Med 2014;35:495-504.

116. Tonelli AR. Pulmonary hypertension survival effects and treatment options in cystic fibrosis. Curr Opin Pulm Med 2013;19(6):652-661.

117. Slieker MG, van Gestel JP, Heijerman HG, Tramper-Stranders GA, van Berkhout FT, van der Ent CK, Jansen NJ. Outcome of assisted ventilation for acute respiratory failure in cystic fibrosis. Intensive Care Med 2006;32:754-758.

118. Ratjen F. Overview of magnetic resonance imaging (MRI) in CF lung disease. Pediatr Pulmonol 2017;52(Suppl 47):202-203.

119. Wielpütz MO, Eichinger M, Biederer J, Wege S, Stahl M, Sommerburg $\mathrm{O}$, et al. Imaging of cystic fibrosis lung disease and clinical interpretation. Rofo 2016;188:834-845.

120. Benden C, Wallis C, Owens CM, Ridout DA, Dinwiddie R. The Chrispin-Norman score in cystic fibrosis: doing away with the lateral view. Eur Respir J 2005;26:894-897.

121. Mott LS, Park J, Gangell CL, de Klerk NH, Sly PD, Murray CP, et al. Distribution of early structural lung changes due to cystic fibrosis detected with chest computed tomography. J Pediatr 2013; 163:243-248.

122. Wielpütz MO, Mall MA. MRI accelerating progress in functional assessment of cystic fibrosis lung disease. J Cyst Fibros 2017;16(2): 165-167.

123. Roach DJ, Crémillieux Y, Fleck RJ, Brody AS, Serai SD, Szczesniak RD, et al. Ultra echo-time magnetic resonance imaging is a sensitive method for the evaluation of early cystic fibrosis lung disease. Ann Am Thorac Soc 2016;13(11):1923-1931.

124. Altes T. Hyperpolarized gases for ventilation and gas exchange. Pediatr Pulmonol 2017;52(Suppl 47):203-204.

125. Mentore K, Froh DK, de Lange EE, Brookeman JR, Paget-Brown AO, Altes TA. Hyperpolarized He 3 MRI of the lung in cystic fibrosis: assessment at baseline and after bronchodilator and airway clearance treatment. Acad Radiol 2005:12(11):1423-1429.

126. Harun S, Wainwright C, Klein K, Hennig S. A systematic review of studies examining the rate of lung function decline in patients with cystic fibrosis. Paediatr Respir Rev 2016;20:55-66.

127. Pittman J. Clinical application of multiple breath washout testing. Pediatr Pulmonol 2017;52(Suppl 47):122-123.

128. Ramsey KA, Rosenow T, Turkovic L, Skoric B, Banton G, Adams $\mathrm{AM}$, et al. Lung clearance index and structural lung disease on computed tomography in early cystic fibrosis. Am J Respir Crit Care Med 2016;193(1):60-67.

129. Saiman L, Siegel JD, LiPuma JJ, Brown RF, Bryson EA, Chambers $\mathrm{MJ}$, et al. Infection prevention and control guidelines for cystic fibrosis: 2013 update. Infect Control Hosp Epidemiol 2014; 35(Suppl 1):S1-S67. 


\section{CF OverVIEW}

130. Linnane B, Collins L, Bussmann N, O’Connell NH, Dunne CP. Medical devices for cystic fibrosis care may be portable reservoirs of potential pathogens. J Hosp Infect 2017;96(4):397-398.

131. O'Malley CA. Device cleaning and infection control in aerosol therapy. Respir Care 2015;60(6):917-927.

132. Manor E, Gur M, Geffen Y, and Bentur L. Cleaning and infection control of airway clearance devices used by CF patients. Chron Respir Dis 2017;14(4):370-376.

133. Morrell MR, Pilewski JM. Lung transplantation for cystic fibrosis. Clin Chest Med 2016;37:127-138.

134. Yusen RD, Edwards LB, Kucheryavaya AY, Benden C, Christie JD, Dipchand AI, et al: The registry of the International Society for Heart and Lung Transplantation: thirty-first adult lung and heartlung transplant report-2014; focus theme: re-transplantation. J Heart Lung Transplant 2014;33:1009-1024.

135. Ramos KJ, Quon BS, Heltshe SL. Heterogeneity in survival in adult patients with cystic fibrosis with FEV1 $<30 \%$ of predicted in the United States. Chest 2017;151(6):1320-1328.

136. Ramos KJ, Quon BS, Psoter KJ, Lease ED, Mayer-Hamblett N, Aitken ML, Goss CH. Predictors of non-referral of patients with cystic fibrosis for lung transplant evaluation in the United States. J Cyst Fibros 2016;15:196-203.

137. Ramos KJ, Somayaji R, Lease ED, Goss CH Aitken ML. Cystic fibrosis physicians' perspectives on the timing of referral for lung transplant evaluation: a survey of physicians in the United States. BMC Pulm Med 2017;17:21.

138. Ramos KJ, Smith PJ, McKone EF, Pilewski JM, Lucy A, Hempstead SE, et al. The CF Lung Transplant Referral Guidelines Committee. J Cyst Fibros 2019;18(3):321-333.
139. Ramsey BW, Davies J, McElvaney NG, Tullis E, Bell SC, Dřevínek P, et al. A CFTR potentiator in patients with cystic fibrosis and the G551D mutation. N Engl J Med 2011;365(18):1663-1672.

140. Wainwright CE, Elborn JS, Ramsey BW, Marigowda G, Huang X, Cipolli M, et al. Lumacaftor-Ivacaftor in Patients with Cystic Fibrosis Homozygous for Phe508- del CFTR. N Engl J Med 2015; 373(3):220-31.

141. Taylor-Cousar JL, Munck A, McKone EF, van der Ent CK, Moeller A, Simard C, et al. Tezacaftor-ivacaftor in patients with cystic fibrosis homozygous for Phe508del. N Engl J Med 2017;377(21): 2013-2023.

142. Rowe SM, Daines C, Ringshausen FC, Kerem E, Wilson J, Tullis E, et al. Tezacaftor-ivacaftor in residual-function heterozygotes with cystic fibrosis. N Engl J Med 2017;377(21):2024-2035.

143. Grasemann H. CFTR modulator therapy for cystic fibrosis. N Engl J Med 2017;377:2085-2088.

144. Middleton PG, Mall MA, Dřevínek P, Lands, LC, McKone, EF, Polineni D, et al. Elexacaftor-tezacaftor-ivacaftor for cystic fibrosis with a single Phe508del allele. N Engl J Med 2019; 381(18):1809-1819.

145. Heijerman HG, McKone EF, Downey DG, Van Braeckel E, Rowe SM, Tullis E, et al. Efficacy and safety of the elexacaftor plus tezacaftor plus ivacaftor combination regimen in people with cystic fibrosis homozygous for the F508del mutation: a double-blind, randomised, phase 3 trial. Lancet 2019 [Epub ahead of print] doi: https://doi.org/10.1016/S0140-6736(19)32597-8.

146. Collins FS. Realizing the dream of molecularly targeted therapies for cystic fibrosis. N Engl J Med 2019;381:1863-1865. 